\title{
Acerca de la justificación de la prisión preventiva y algunas críticas frecuentes
}

\author{
Diego Dei Vecchi*
}

\begin{abstract}
RESUMEN
El presente texto se ocupa de la justificación de la premisa normativa en las decisiones judiciales aplicativas de la prisión preventiva frente a ciertas críticas doctrinarias hoy frecuentes. Para ello, se reconstruye en primer término la concepción doctrinaria mayoritaria de la prisión preventiva que algunos denominan "concepción cautelar". Se muestra luego que las premisas normativas en que los jueces basan sus decisiones responden a esa concepción doctrinaria, lo que se verifica en una pluralidad de ordenamientos jurídico-procesales que en muchos otros aspectos son muy divergentes. Se presentan luego algunas críticas, en general también provenientes de la doctrina, que alegan la ilegitimidad de la prisión preventiva así concebida.
\end{abstract}

Prisión preventiva - concepción cautelar - justificación

\section{The justification of preventive detention and some frequent criticisms}

\begin{abstract}
This paper analyses the justification of the normative premise in judicial decisions applied to preventive detention and examines some frequent criticisms. For this purpose, it firstly reconstructs the dominant doctrinal conception of preventive detention, which some refer to as 'precautionary conception'. Further, it shows that the normative premises on which judges base their decisions embrace this doctrinal conception, which is confirmed in a number of procedural arrangements that in many other aspects are very heterogeneous. Subsequently, it presents some doctrinal criticisms that claim the illegitimacy of this conception of preventive detention.
\end{abstract}

Preventive detention - precautionary conception - justification

* Abogado, Magíster en Derecho y Argumentación, Investigador del Dipartimento Giovanni Tarello, U. de Génova, Italia. Correo electrónico: deivecchidm@gmail.com.

Artículo recibido el 30 de agosto de 2013 y aceptado para su publicación por el Comité Editorial el 28 de octubre de 2013.

ABREVIATURAS: Tribunales: $\mathrm{CIDH}=$ Corte Interamericana de Derechos Humanos; $\mathrm{CoIDH}=$ Comisión Interamericana de Derechos Humanos; $\mathrm{CEDH}=$ Corte Europea de Derechos Humanos (Corte de Estrasburgo); $\mathrm{CSCh}=$ Corte Suprema de Chile; $\mathrm{CSJN}=$ Corte Suprema de Justicia de la Nación Argentina; $\mathrm{CCI}=$ Corte Costituzionale Italiana; $\mathrm{Cc}=$ Corte Cassazione italiana; TSJC $=$ Tribunal Superior 


\section{INTRODUCCIÓN}

$\mathrm{L}$ a cuestión de resolver si un individuo ha de permanecer en libertad durante el proceso penal seguido en su contra o si, por el contrario, ha de ser encarcelado preventivamente, constituye una de las cuestiones más controvertidas a lo largo de la historia del derecho procesal penal. Sobre todo frente a ciertos postulados presentes hoy en la mayor parte de los ordenamientos constituciones occidentales que parecen apoyar la afirmación de que tal encarcelamiento resulta ilegítimo ${ }^{1}$. Enfocada la cuestión desde el punto de vista del legislador, este ha sido un problema clásico en el diseño del ordenamiento procesal en lo que a la formulación de los textos respecta ${ }^{2}$. Pero habiendo sido en general admitida, al menos prima facie, la posibilidad de encarcelamiento preventivo en la generalidad de los textos normativos pertinentes de la cultura jurídica occidental, la cuestión se ha convertido en un problema para los jueces sobre cuyas espaldas recae el peso de dotar de contenido a esas disposiciones enmarcándolas

de Justicia de Córdoba (Argentina); USC = United States Supreme Court; CNCP = Cámara Nacional de Casación Penal (Argentina); Legislación internacional. Legislación $=$ DUDH $=$ Declaración Universal de Derechos Humanos, ONU, 1948; DADDH = Declaración Americana de Derechos y Deberes del Hombre, Bogotá, 1948; CADH = Convención Americana de Derechos del Hombre, San José de Costa Rica, 1969; $\mathrm{CEDH}=$ Convención Europea de Derechos Humanos, Roma 1950; CDFU = Carta de Derechos Fundamentales de la Unión Europea, Niza 2000; CE = Constitución Europea; CN = Constitución Nacional Argentina; Cost. $=$ Costituzione Italiana. Códigos procesales penales argentinos** $=\mathrm{CPPN}=$ Código Procesal Penal de la Nación; CPPC = Código Procesal Penal de la provincia de Córdoba; CPPSC = Código Procesal Penal de la provincia de Santa Cruz; CPPTF = Código Procesal Penal de la provincia de Tierra del Fuego; $\mathrm{CPPCh}=$ Código Procesal Penal de la provincia de Chubut; $\mathrm{CPPRN}=$ Código Procesal Penal de la provincia de Río Negro; CPPLP = Código Procesal Penal de la provincia de La Pampa; CPPBA = Código Procesal Penal de la provincia de Buenos Aires; CPPCABA = Código Procesal Penal de la Ciudad Autónoma de Buenos Aires; $\mathrm{CPPM}=$ Código Procesal Penal de la provincia de Mendoza; $\mathrm{CPPSJ}=\mathrm{Código}$ Procesal Penal de la provincia de San Juan; CPPSL = Código Procesal Penal de la provincia de San Luis; $\mathrm{CPPT}=$ Código Procesal Penal de la provincia de Tucumán; $\mathrm{CPPSE}=$ Código Procesal Penal de la provincia de Santiago del Estero; $\mathrm{CPPCrr}=$ Código Procesal Penal de la provincia de Corrientes; $\mathrm{CPPER}=$ Código Procesal Penal de la provincia de Entre Ríos; CPPMs = Código Procesal Penal de la provincia de Misiones; $\mathrm{CPPC} c o=$ Código Procesal Penal de la provincia del Chaco CPPSt $=$ Código Procesal Penal de la provincia de Salta; CPPJ = Código Procesal Penal de la provincia de Jujuy; CPPLR = Código Procesal Penal de la provincia de La Rioja. Otros códigos procesales penales = c.p.p. = Codice di procedura penale italiano. LEP = Ley de Enjuiciamiento penal.

** Los códigos de los demás países latinoamericanos serán citados mencionando en cada caso el país correspondiente luego de CPP.

${ }^{1}$ Si bien podría ser motivo de discusión, referiré aquí a "ordenamientos constitucionales" haciendo referencia a los "bloques constitucionales" en su totalidad, incluidos los instrumentos internacionales a que en cada estado se reconoce jerarquía constitucional. Tomo la expresión "bloques constitucionales" de Bidart Campos, G. J., Tratado elemental de Derecho constitucional argentino, I-A, EDIAR, Buenos Aires, 2000, p. 413.

2 “... pues el derecho procesal penal no hace más que reglamentar o dar vida práctica a esos dogmas constitucionales, donde yacen las bases del sistema instrumental predispuesto para administrar justicia" (Vélez Mariconde, A., Derecho procesal penal, 1, Marcos Lerner, Córdoba, Argentina, 1986, p. 313, en el mismo sentido, Maier, J.B., Derecho Procesal Penal: Fundamentos, 1, del Puerto, Buenos Aires, 2004, p. $162-$ 163, Pastor, D. R., "El encarcelamiento preventivo", Tensiones: ¿Derechos fundamentales o persecución penal sin limites?, Editores del Puerto, Buenos Aires, 2004, 147-164, p. 149). 
en el cuadro constitucional. Desde este último enfoque, el de la decisión judicial, es que el tema intentará aquí abordarse.

En este sentido, es usual entre los teóricos del derecho reconstruir a la decisión judicial como un silogismo donde de una premisa mayor, normativa, y de una premisa menor, fáctica, se deduce por modus ponens una conclusión (la llamada decisión norma). Dicho silogismo deductivo hace a la justificación interna en tanto que la justificación de cada una de las premisas que lo conforman hace a la llamada justificación externa ${ }^{3}$. Se analizará aquí la justificación (externa) de la premisa normativa de la prisión preventiva, i.e. la justificación de la norma que dispone que en ciertas circunstancias, ciertos individuos, deban ser encarcelados durante un proceso penal. Puede decirse a estos efectos que la justificación de la premisa normativa consiste en dar razones en favor de cierta interpretación de un determinado (o un grupo de determinados) enunciado normativo. Como posiblemente en cualquier otra materia, es la interpretación judicial la que determina la identidad de la premisa normativa de la decisión y es la argumentación ofrecida en favor de esa interpretación la que eventualmente justifica esa premisa ${ }^{4}$. En este trabajo pondré de manifiesto que, en lo que a la decisión aplicativa de la prisión preventiva respecta, se detecta una uniformidad relevante en la fijación de la premisa normativa por parte de decisores vinculados con diversos ordenamientos jurídicoprocesales; ordenamientos sumamente divergentes en muchos otros aspectos. Traeré a colación que, aunque esto no es algo en absoluto novedoso, esta uniformidad responde a la adopción de una serie de argumentos de origen predominantemente doctrinario, formulados en vistas a compatibilizar el encarcelamiento preventivo con ciertas exigencias (de los bloques) constitucionales (principalmente la presunción de inocencia). Esos argumentos doctrinarios constituyen lo que suele denominarse concepción cautelar de la prisión preventiva. Comenzaré con un breve repaso histórico del ingreso de la presunción de inocencia a los sistemas jurídicos occidentales, sobre todo, a los fines de ubicar las bases de la concepción cautelar de la prisión preventiva en las ideas de los pensadores que defendieron la positivización de tal principio. Haré una breve referencia a la modernización de esa concepción para mostrar posteriormente cómo ella se detecta, hasta hoy, en gran parte de las premisas normativas de las decisiones judiciales que aplican la prisión preventiva. A partir de allí intentaré reconstruir ciertos argumentos críticos dirigidos a la concepción cautelar que alegan la inconstitucionalidad de las premisas normativas basadas en esa concepción ${ }^{5}$. Pretendo mostrar aquí que muchos

${ }^{3}$ Por todos, Atienza, M., Las razones del derecho: teorías de la argumentación jurídica, Universidad Nacional Autónoma de México, México, 2003, p. 166, Wróblewski, J., "Legal Syllogism and Rationality of Judicial Decision”, en Rechtstheorie, 5, 1974, 33-46, p. 34, Wróblewski, J., Sentido y becho en el derecho, Distribuciones Fontamara, México, 2008, p. 52

${ }^{4}$ La fijación de la premisa normativa, por lo demás, determina la premisa fáctica a probar (Cfr. Ferrer Beltrán, J., La valoración racional de la prueba, Marcial Pons, Madrid, 2007, p. 130). Si bien los problemas relacionados con la justificación de la premisa fáctica de la decisión judicial referida a la prisión preventiva son sumamente relevantes, ellos no podrán ser tratados aquí.

${ }^{5}$ Es por ello que las denomino críticas radicales o abolicionistas. Usa el segundo término, entre otros, Ferrer Beltrán, J., "Una concepción minimalista y garantista de la presunción de inocencia”; Girona: 
de los argumentos críticos no logran dar en el blanco y que, en lo que constituye un genuino desacuerdo, la cuestión trasciende al plano jurídico aun cuando tenga el efecto de minar los cimientos de la concepción cautelar ${ }^{6}$.

\section{LA Historia OFICIAL DE LA PRESUNCIÓN DE INOCENCIA Y LOS ORÍGENES DE LA CONCEPCIÓN CAUTELAR DE LA PRISIÓN PREVENTIVA}

Es un lugar común entre los procesalistas "continentales" el de situar a fines del siglo XVIII el germen de lo que muchos denominan el "cambio de paradigma” del sistema de enjuiciamiento penal: aquel que habría dejado atrás al sistema de enjuiciamiento inquisitivo a partir del rechazo de algunos de sus postulados básicos. En particular, y en lo que aquí importa, a partir del rechazo de la presunción de culpabilidad, de la concepción de imputado como "objeto" de investigación "socialmente peligroso", y del abandono de la consecuente concepción ("sustantivista”) de la privación de la libertad durante el proceso como medio insoslayable de protección social ${ }^{7}$. El rechazo categórico de ese sistema de enjuiciamiento y de sus postulados de base coincide con aquello que se ha denominado la "historia oficial" de los derechos humanos, especialmente en lo

Universitat de Girona, 2010. Los autores expresan esta crítica con términos como ilegitimidad, inconstitucionalidad, inmoralidad, injusticia, etc. (entre otros pueden verse, Bovino, A., "Contra la inocencia", en Revista electrónica de derecho penal, derecho procesal penal y criminología, 2005b, Bovino, A., "Un Voto Cínico. A propósito del Voto de Riggi en el caso Chabán”, en Nueva Doctrina Penal, 1, 2006, 127-157, Carrara, F., "Inmoralità del carcere preventivo", Programma del corso di diritto criminale: del giudizio criminale, Il Mulino, Bologna, 2004 [1872], 401-405, Ferrajoli, L., Derecho y razón: teoría del garantismo penal, Trotta, Madrid, 2005, Martini, F. M., "Ilegitimidad del encarcelamiento preventivo” (Universidad Nacional de Córdoba, 2010), Vitale, G., Encarcelamiento de presuntos inocentes: Hacia la abolición de una barbarie, Hammurabi, Buenos Aires, 2007, Zaffaroni, E. R., A. Alagia, \& A. Slokar, Manual de derecho penal: parte general, Ediar, Buenos Aires, 2006). Naturalmente, el abolicionismo al que aquí se alude refiere exclusivamente a la prisión preventiva, no a la pena ni al derecho penal integralmente considerado. Es, por tanto, una tesis independiente a la del abolicionismo penal (cfr., entre otros, Ferrajoli, L., Derecho y razón: teoría del garantismo penal, Trotta, Madrid, 2005, p. 251-252, Zaffaroni, E. R., A. Alagia, \& A. Slokar, Manual de derecho penal: parte general, Ediar, Buenos Aires, 2006, p. 278).

${ }^{6}$ No trataré en este texto una serie de críticas específicas dirigidas limitadamente a algunos motivos de procedencia de la prisión preventiva previstos en algunos ordenamientos procesales. Se trata de motivos de procedencia de la prisión preventiva que se introducen, acaso enmascaradamente, como casos de "peligro para los fines del proceso" (e.g. "repercusión social del hecho", "peligro de daño para terceros", "evitación de la continuidad en la actividad delictiva”, etc.). Llamo a estas críticas, relativas, debido a que no alegan sin más la ilegitimidad de la prisión preventiva.

${ }^{7}$ Esto es, como verdadera pena: medio de represión o de prevención ya sea general o especial. Sobre el punto, Cordero, F., Riti e sapienza del diritto, Laterza, Roma-Bari, 1981, p. 625-658, Cordero, F., La fabbrica della peste, Laterza, Roma, 1984. Sobre el origen del sistema inquisitivo ver también Maier, J.B., Derecho Procesal Penal: Fundamentos, 1, del Puerto, Buenos Aires, 2004, p. 450. Ello suele vincularse también con la finalidad inquisitiva esencial cual habría sido la de obtener la confesión del imputado (Ferrajoli, L., Derecho y razón: teoría del garantismo penal, Trotta, Madrid, 2005, p. 551). 
relativo a la recepción positiva ${ }^{8}$, entre otros, del principio de presunción de inocencia: el derecho de toda persona a ser considerada inocente hasta que una condena recaída en un procedimiento con ciertas características especiales (i.e. el "debido proceso") establezca lo contrario?.

Desde ese entonces y hasta hoy, suele decirse, la presunción de inocencia define en sí mismo al sistema de enjuiciamiento debido a las implicancias que acarrea ${ }^{10}$. En lo que aquí interesa, tradicionalmente se derivaron de la presunción de inocencia ciertas reglas específicas. Entre ellas, la "regla de tratamiento" del imputado cual inocente y la "regla de juicio". Esta última, se dice usualmente, implica por un lado que la responsabilidad probatoria de la hipótesis delictiva recae sobre la acusación y, por el otro, que ha de absolverse al imputado si la prueba es insuficiente para aceptar dicha hipótesis como verdadera ${ }^{11}$. Como regla de trato del imputado, la presunción de inocencia implicaría un verdadero contrapeso, si no obstáculo insalvable, frente a la pretensión de encarcelar a un individuo no declarado culpable: ¿cómo explicar el encarcelamiento de aquel que debe ser tratado como inocente si no ha sido condenado? Sin embargo, la propia Declaración de derechos del hombre de 1789, estandarte iluminista del cambio de paradigma, admitía la posibilidad de encarcelamiento previo a condena, estableciendo en su artículo 9, luego de consagrar genéricamente la presunción de inocencia, que el "arresto" podría efectuarse en casos de extrema necesidad al margen de los cuales habría de considerarse ilegítimo ${ }^{12}$. Entre los intelectuales que inspiraron el cambio

${ }^{8}$ Esto es, el “... proceso que conduce a la llamada 'fase declarativa' o de 'positivización' de ese ideal de justicia, proceso que culminaría con la Declaración de Independencia estadounidense de 1776 y la Declaración de Derechos del Hombre y del Ciudadano de 1789" (De Lora, P., Memoria y frontera el desafío de los derechos bumanos, Alianza, Madrid, 2008, p. 31-32).

9 Sobre la idea de "debido proceso" ver, por todos, Ferrua, P., Studi sul processo penale: declino del contraddittorio e garantismo reattivo, III, Giappichelli, Torino, 1997.

${ }^{10}$ Carrara, F., "Il diritto penale e la procedura penale", Programma del corso di diritto criminale: del giudizio criminale, Il Mulino, Bologna, 2004 [1873-74], 415-441, p. 424-425. Cfr. Binder, A. M., Introducción al derecho procesal penal, Ad-Hoc, Buenos Aires, 2009, p. 133, Grevi, V., "Presunzione di non colpevolezza, garanzie dell'imputato ed efficienza del processo nel sistema costituzionale”, en Penale, A. T. G. S. D. P., Presunzione di non colpevolezza e disciplina delle impugnazioni, Giuffrè, Milano, 2000, 15-62, p. 15-16, Illuminati, G., La presunzione d'innocenza dell'imputato, Zanichelli, Bologna, 1979, p. 5.

${ }^{11}$ Sobre el punto Fernández López, M., Prueba y presunción de inocencia, Iustel, Madrid, 2005, p. 139, Ferrer Beltrán, J., "Una concepción minimalista y garantista de la presunción de inocencia”, Paulesu, P. P., La presunzione di non colpevolezza dell'imputato, 30, G. Giappichelli, Torino, 2009, p. 10. Estos aspectos "probatorios" de la presunción de inocencia, se dice, son prioritarios en el common law (entre otros, Batia, G. \& A. Pizzo, "La tutela dell'imputato-Saggio storico- concettuale", 2011). La preeminencia de la "regla de juicio" no se debe, sin embargo, al desconocimiento de la regla de trato del imputado cual inocente, sino, más bien, a que el sistema acusatorio ha sido permanentemente predominante en los países anglosajones (véase Maier, J.B., Derecho Procesal Penal: Fundamentos, 1, del Puerto, Buenos Aires, 2004, p. 443-449). Por razones de extensión, los aspectos probatorios no serán tratados en este trabajo, ni en términos generales ni en términos específicamente relacionados con la presunción de inocencia o con la prisión preventiva, aunque mantengo la convicción de que una dilucidación del modo en que esos aspectos se resuelven en las decisiones judiciales aplicativas de la prisión preventiva pone en jaque a la concepción cautelar de la prisión preventiva.

12 Art. 9 Declaración de derechos del hombre: “Todo hombre ha de ser tenido por inocente hasta que haya sido declarado culpable, y si se juzga indispensable detenerle, todo rigor que no fuere necesario para asegurarse de su persona debe ser severamente reprimido por la ley". Sobre las interpretaciones de que fue 
de paradigma aludido, el propio Beccaria estimaba legítimo el encarcelamiento previo a condena en ciertos casos, "[l] a carcere è dunque la semplice custodia d'un cittadino finché sia giudicato reo, e questa custodia essendo essenzialmente penosa, deve durare il minor tempo possibile e dev'essere meno dura che si possa. Il minor tempo dev'essere misurato e dalla necessaria durazione del processo e dall'anzianità di chi prima ha un diritto di esser giudicato. La strettezza della carcere non può essere che la necessaria, o per impedire la fuga, o per non occultare le prove dei delitti" ${ }^{13}$. De este modo, la presunción de inocencia se entendía desde el primer momento como prohibición de trato al imputado en idéntico modo y con idéntica finalidad en relación con el condenado. Si, por el contrario, el encarcelamiento no fuere concebido en idéntico modo y/o con idéntica finalidad respecto de la pena, pues entonces no estaría dicho que fuere ilegítimo, al menos no a la luz de la presunción de inocencia. Pero la apuesta era aún más notable, ya que se afirmaba que si el encarcelamiento fuere dispuesto en vistas de la tutela exclusiva de los fines del proceso penal, no solo no resultaría ilegítimo por "no ser pena”, sino que estaría además justificado. Decía Carrara hace ya casi doscientos años que la prisión preventiva "[p]ure si ammette come una necessità politica ormai riconosciuta per i seguenti bisogni $-1^{\circ}$ bisogno di giustizia; per impedire la fuga del reo $-2^{\circ}$ bisogno di verità; per impedirgli d'intorbidare le ricerche dell'autorità, distruggere le vestigia del delitto, intimidare i testimoni $-3^{\circ}$ bisogno di pubblica difesa: per impedire a certi facinorosi di continuare pendente il processo nei loro attacchi al diritto altrui" 14 . En este sentido, el "cambio de paradigma”, los sucesos que lo precedieron y los argumentos políticos, morales y jurídicos a él subyacentes, en lo referente a la prisión preventiva significaron una mera "alteración de concepción”, como ha dicho Ferrajoli más peyorativamente, un fraude de etiqueta ${ }^{15}$.

A esto han de agregarse los resabios de dos momentos históricos ulteriores en que la legitimación de la prisión preventiva se vio reforzada precisamente por los ataques a la presunción de inocencia ${ }^{16}$. El primero de esos momentos se identifica con el auge de

objeto esta disposición normativa en concreto ver, Paulesu, P. P., La presunzione di non colpevolezza dell'imputato, 30, G. Giappichelli, Torino, 2009, p. 35.

${ }^{13}$ Beccaria, C., Dei delitti e delle pene, Verona, 1996 [1764], p. 60. Y en el mismo sentido, si bien la gran mayoría de los intelectuales de la época pedían la limitación, "[n]inguno de ellos llega, sin embargo, a pedir coherentemente la supresión del vituperado instituto: cual si se tratase de una 'injusticia necesaria”"(Ferrajoli, L., Derecho y razón: teoría del garantismo penal, Trotta, Madrid, 2005, p. 552, ver al respecto la bibliografía por él citada. En particular notas 31 a 49); "la Ilustración y el liberalismo nunca se propusieron abolir el encarcelamiento preventivo (la prisión durante el procedimiento penal)..." (Maier, J.B., Derecho Procesal Penal: Actos Procesales, 3, del Puerto, Buenos Aires, 2011, p. 380).

${ }^{14}$ Carrara, F., Programma del corso di diritto criminale: del giudizio criminale, Il Mulino, Bologna, 2004 [1859], p. 161-162 § 897. En el mismo sentido Carrara, F., "Inmoralità del carcere preventivo", Programma del corso di diritto criminale: del giudizio criminale, Il Mulino, Bologna, 2004 [1872], 401-405, p. 401-402.

${ }^{15} \mathrm{Y}$ esta tibieza trasciende a la legitimación de la prisión preventiva y se manifiesta también en otros postulados aparentemente contrarios a las pretensiones reformistas y definitorios de la mixtura del actual sistema de enjuiciamiento. Tales los de persecución penal pública obligatoria, investigación parcialmente secreta y predominantemente escrita, facultades probatorias del juzgador, etcétera.

${ }^{16}$ Cfr. Batia, G. \& A. Pizzo, "La tutela dell' imputato -Saggio storico- concettuale”, Paulesu, P. P., La presunzione di non colpevolezza dell'imputato, 30, G. Giappichelli, Torino, 2009, p. 30-50. 
las ideas del positivismo criminológico, cuyos exponentes rechazaron el principio de presunción de inocencia sobre la base de la visión global que poseían acerca del fenómeno penal: considerar inocentes a acusados biológicamente predispuestos al crimen resultaba irracional desde todo punto de vista. La prisión preventiva era de tal modo una medida de protección social paradigmática e indispensable ${ }^{17}$. El segundo momento de crisis para la presunción de inocencia, y consecuente reforzamiento de la prisión preventiva, se debió al auge de las ideas de la llamada "Escuela técnico-jurídica" cuyos máximos exponentes fueron Alfredo Rocco y Vincenzo Manzini. El primero de ellos sostenía que la presunción de inocencia es, "una stravaganza derivante da quei vieti concetti, germogliati dai principi della Rivoluzione francese, per cui si portano ai più esagerati e incoerenti eccessi le garanzie individuali" ${ }^{18}$. La estrategia argumental de quienes formaban parte de esta escuela, contaminada con alguna clase de positivismo ideológico, consistía en mostrar la incompatibilidad de estos "principios éticos" con ciertos institutos positivamente vigentes, entre ellos, la prisión preventiva. Si hay que presumir la inocencia del imputado, decía Manzini, ¿por qué entonces se procede en su contra ${ }^{19}$ ? Las ideas de esta escuela se plasmaron en el

17 Así, Garofalo, R., "La detenzione preventiva”, en La Scuola Positiva, 2, 1892, 199. Pueden verse también por todos, Batia, G. \& A. Pizzo, "La tutela dell' imputato-Saggio storico-concettuale”, pp. 19-20, Ferrajoli, L., Derecho y razón: teoría del garantismo penal, Trotta, Madrid, 2005, p. 550, Ferri, E., Sociologia criminale, Fratelli Bocca, Torino, 1892, Garofalo, R., Criminologia: studio sul delitto, sulle sue cause e sui mezzi di repressione, Fratelli Bocca, Roma [etc.], 1885.

18 Rocco, A., "Relazione al progetto preliminare del codice di Procedura Penale", en Italia, M. D. G. E. D. a. D. C., Lavori preparatori del Codice penale e del Codice di procedura penale, VIII, Tipografia delle Mantellate, Roma, 1929, 295 p, p. 22.

19 Manzini, V., Manuale di procedura penale italiana, Fratelli Bocca, Roma [etc.], 1912, p. 53. Sobre las contradicciones en la argumentación de Manzini véase Batia, G. \& A. Pizzo, "La tutela dell' imputato-Saggio storico- concettuale”, p. 21, en particular nota 96. Allí ha de buscarse también la distinción atribuida a Ludovico Mortara y que también llegaría a latinoamérica, entre presunción de inocencia (ajena al derecho positivo) y presunción de no culpabilidad que importaría un tertius genus entre las situaciones jurídicas de inocencia y de culpabilidad: la del imputado. Esta distinción se cristalizaría en el vigente art. 27 comma 2 de la Constitución italiana. Sobre el punto, que excede los límites de este trabajo, ver Cordero, F., Procedura penale, Giuffrè, Milano, 2003, p. 471, De Caro, A., Libertà personale e sistema processuale penale, Edizioni Scientifiche Italiane, Napoli-Roma, 2000, p. 205, Falzone, V., F. Palermo, \& F. Cosentino, La Costituzione della Repubblica italiana: illustrata con i lavori preparatori e corredata da note e riferimenti, Arnoldo Mondadori, Milano, 1976, p. 11, Ferrua, P., "Il giudizio penale: fatto e valore giuridico", en A.A.V.V., La prova nel dibattimento penale, G. Giappichelli, Torino, 2007, 317-410, p. 358, Garofoli, V., "Presunzione d'innocenza e considerazione di non colpevolezza. La fungibilitá delle due formulazioni”, en Penale, A. T. G. S. D. P., Presunzione di non colpevolezza e disciplina delle impugnazioni, Giuffrè, Milano, 2000, 63-104, p. 64-65, Garofoli, V., "Presunzione d'innocenza e considerazione di non colpevolezza. La fungibilitá delle due formulazioni”, en Penale, A., Presunzione di non colpevolezza e disciplina delle impugnazioni, Giuffrè, Milano, 2000, 63-104, Giocoli Nacci, P., "Procedimento de libertate e giudicato cautelare", en Penale, A. T. G. S. D. P., Il significato del principio costituzionale di non colpevolezza dell'imputato, Giuffrè, Milano, 2000, 231-238, p. 233, Giunchedi, F., La tutela dei diritti umani nel processo penale, CEDAM, Padova, 2007, p. 66, Paulesu, P. P., La presunzione di non colpevolezza dell'imputato, 30, G. Giappichelli, Torino, 2009, p. 57, Paulesu, P. P., La presunzione di non colpevolezza dell'imputato, 30, G. Giappichelli, Torino, 2009, p. 56, Pisapia, G. D., Compendio di procedura penale, CEDAM, Padova, 1985, p. 52. 
Codice di procedura penale italiano de 1930, conocido como "Código Rocco"20, y mediante dicho cuerpo normativo llegaron posteriormente a Latinoamérica, especialmente con el Código Procesal Penal de la provincia argentina de Córdoba de 1939, que impulsó una etapa de reformas legislativas dentro de ese país y que se extendió además a muchos códigos latinoamericanos, algunos aún vigentes ${ }^{21}$.

Por lo demás, lo que caracterizó a los siglos XX y XXI, aun cuando no se hayan verificado grandes cambios en lo que al enjuiciamiento penal respecta (al menos en comparación con el siglo precedente) es el fenómeno de positivización "universalizada" de los "derechos fundamentales" 22 . Entre ellos, el principio de presunción de inocencia y el derecho a la libertad ambulatoria durante el proceso penal ${ }^{23}$. En este sentido, parece ser hoy posición holgadamente mayoritaria aquella según la que presunción de inocencia y derecho a la libertad, por una parte, y prisión preventiva por la otra, marcan mutua y universalmente sus respectivos límites ${ }^{24}$. Como para los “iluministas”, esos límites estarían dados por la finalidad del encarcelamiento sin condena: la finalidad de neutralizar peligros procesales imposibles de tutelar por otros medios. Es esa finalidad la que marca el límite entre la reglamentación de los derechos constitucionales a la libertad durante el proceso y a la presunción de inocencia y su violación ${ }^{25}$. La sofisticación del

${ }^{20}$ Sobre la influencia de Manzini sobre este código ver Garofoli, V., "Presunzione d’innocenza e considerazione di non colpevolezza. La fungibilitá delle due formulazioni”, en Penale, Presunzione di non colpevolezza e disciplina delle impugnazioni, Giuffrè, Milano, 2000, 63-104, p. 76 y nota 50 en la misma página.

${ }^{21}$ Véanse, Alvarado Velloso, A., Introducción al estudio del derecho procesal, 1, Rubinzal-Culzoni, Santa Fe, 2008, p. 70, Clariá Olmedo, J. A., Derecho Procesal Penal, 1, Marcos Lerner, Córdoba, 1984, p. 130, Maier, J.B., Derecho Procesal Penal: Fundamentos, 1, del Puerto, Buenos Aires, 2004, p. 464. Alcalá Zamora decía que "no deja de ser paradójico que la congruencia (del sistema procesal) con la Constitución liberal y democrática de 1853 (...) se buscase en el Código de la monarquía fascista italiana de 1930" (La reforma del procedimiento penal argentino, citado por Vélez Mariconde, A., Derecho procesal penal, 1, Marcos Lerner, Córdoba, Argentina, 1986, p. 147, nota 37). Véase también, en el caso de Chile la "Historia de la Ley N 19.696", Código Procesal Penal de la República de Chile, 12 de octubre, 2000 construida por la Biblioteca del Congreso Nacional (disponible en http://www.bcn.cl/histley/lfs/hdl-19696/HL19696.pdf).

${ }^{22}$ Cfr. Bulygin, E., "Sobre el estatus ontológico de los derechos humanos", en Doxa: Cuadernos de Filosofía del Derecho, 4, 1987, 79-85.

${ }^{23}$ Sin ánimo de exhaustividad dan cuenta de ello los arts. XXVI primera parte DADDH, 8.2 CADH, 14.2 PIDCP, 11.1 DUDH, 6 parte 2 CEDH, 48.1 CDFU, 108.1 CE.

${ }^{24}$ Sobre la conjugación de estos postulados, ver Bargis, M., "Procedimento de libertate e giudicato cautelare", en Penale, A. T. G. S. D. P., Presunzione di non colpevolezza e disciplina delle impugnazioni, Giuffrè, Milano, 2000, 165-191, p. 165, Carcano, D. \& A. Fojadelli, "Custodia cautelare" e libertà personale, CEDAM, Padova, 1985, p. 27, Grevi, V., "Presunzione di non colpevolezza, garanzie dell'imputato ed efficienza del processo nel sistema costituzionale", en Penale, Presunzione di non colpevolezza e disciplina delle impugnazioni, Giuffrè, Milano, 2000, 15-62, p. 17, Maier, J.B., Derecho Procesal Penal: Fundamentos, 1, del Puerto, Buenos Aires, 2004, p. 512, Ottaviano, S., “¿Libertad provisional' o 'derecho a la libertad'?: La libertad del imputado durante el proceso a la luz de los instrumentos internacionales de derechos humanos”, en Revista de Derecho Procesal Penal: excarcelación, 2005, 393-426, p. 412, Paulesu, P. P., La presunzione di non colpevolezza dell'imputato, 30, G. Giappichelli, Torino, 2009, p. 72, Solimine, M.A., Tratado sobre las causales de excarcelación y prisión preventiva en el Código Procesal Penal de la Nación, Ad-Hoc, Buenos Aires, 2003, p. 642-643.

${ }^{25}$ Pessoa, N. R., "En torno a la libertad durante el proceso penal", en Revista de Derecho Procesal Penal: excarcelación, 2005, 57-68, p. 60. Así vista la cuestión, las palabras de Carrara o de Beccaria antes transcritas bien podrían constituir la premisa normativa de una decisión judicial que dispusiera hoy, y en diversos ordenamientos procesales del mundo, encerrar a un individuo sin condena. En idéntico sentido, muchos autores contemporáneos, ver por todos Chiara Díaz, C., "El proceso penal y la coerción personal", en Revista 
discurso contemporáneo en comparación con la concepción de los "iluministas" radica, en el mejor de los casos, en la utilización de la noción de medida cautelar, importada del derecho procesal civil. Se trata de medidas provisorias e instrumentales, no fines en sí mismas $^{26}$, cuya aplicación está subordinada siempre a la corroboración de dos clases de circunstancias fácticas: (i) la apariencia de buen derecho, esto es, el juicio de probabilidad de que aquella hipótesis en cuyo favor la medida se dispone, sea acogida en la decisión final (lo que se conoce como fumus bonis iuris); (ii) la probabilidad de frustración del derecho implicado en esa hipótesis de no ser aplicada la cautelar (lo que se conoce como periculum in mora $)^{27}$. Como medida cautelar, sostienen los autores, la prisión preventiva compartiría por tanto los caracteres de toda medida del género entre los que están los de instrumentalidad $^{28}$, excepcionalidad ${ }^{29}$, legalidad $^{30}$ y jurisdiccionalidad ${ }^{31}$. Esto último

de Derecho Procesal Penal: excarcelación, 2005, 13-33, p. 16, Grevi, V., "Presunzione di non colpevolezza, garanzie dell'imputato ed efficienza del processo nel sistema costituzionale", en Penale, Presunzione di non colpevolezza e disciplina delle impugnazioni, Giuffrè, Milano, 2000, 15-62, p. 25.

26 Por todos, Calamandrei, P., Introduzione allo studio sistematico del provvedimenti cautelari, CEDAM, Padova, 1936, Chiovenda, G., Istituzioni di diritto processuale civile, I, Eugenio Jovene, Napoli, 1953, Chiovenda, G., Principii di diritto processuale civile, Eugenio Jovene, Napoli, 1965.

27 "La funzione dei provvedimenti cautelari nasce dunque dalla relazione che passa tra due termini: la necessità che il provvedimento, per esser praticamente efficace, sia emanato senza ritardo, e le inettitudine del processo ordinario a creare senza ritardo un provvedimento definitivo" (Calamandrei, P., Introduzione allo studio sistematico del provvedimenti cautelari, CEDAM, Padova, 1936, p. 19). Se ha dicho que, llevado a la prisión preventiva, este discurso, “... capta perfectamente la naturaleza y fines del encarcelamiento preventivo asignándole solo la misión de custodiar los fines del proceso, para que este pueda cumplir su función instrumental de 'afianzar la justicia'” (Cafferata Nores, J. I., La excarcelación, I, Depalma, Buenos Aires, 1988, p. 12).

${ }^{28}$ En el sentido de ser instrumentales al proceso, a su vez instrumento de aplicación de la ley: "strumento dello strumento" (Calamandrei, P., Introduzione allo studio sistematico del provvedimenti cautelari, CEDAM, Padova, 1936, p. 22).

${ }^{29}$ En el sentido de ser la medida el último recurso a aplicar. En la jurisprudencia y doctrina italianas se habla en este sentido de "principio di minore sacrificio necessario" que guía al llamado principio di adeguatezza. Entre nosotros se habla de ultima ratio o de indispensabilidad. Ello se encuentra también en la doctrina procesal civilística (Calamandrei, P., Introduzione allo studio sistematico del provvedimenti cautelari, CEDAM, Padova, 1936, p. 17). Si bien este trabajo no tiene pretensiones sociológico-descriptivas, vale la pena tener presente que la excepcionalidad de la prisión preventiva está lejos de ser una característica de nuestras sociedades, lo que la convierte en un problema real por no ser como debe ser. A título meramente ejemplificativo pueden tenerse presentes las siguientes estadísticas: “... en Córdoba capital 73,02\% de los internos no tiene condena firme y -de esa mayoría- 48\% es joven de entre 18 y 25 años” (http://www.comercioyjusticia.com.ar/2012/09/04/ la-mitad-de-los-presos-apenas-supera-30-anos/). "En algunas provincias hay hasta $70 \%$ de población penal con prisión preventiva” (http://www.comunicacion.rionegro.gov.ar/desarro_noti.php?cod=4279). "La estadística más reciente suministrada por la dirección general de prisiones indica que el $86 \%$ de los presos en los recintos carcelarios dominicanos son preventivos" (John Garrido, para www.carlosparma.com.ar). En Chile la reforma procesal habría tenido un efecto positivo, aunque los porcentajes seguirían siendo altos. Cfr. Ortiz Díaz, C., "Sobre prisión preventiva, y relación con el supuesto de peligrosidad: Análisis contemporáneo, soluciones y consideraciones del supuesto de peligrosidad”, http://www.lexweb.cl/: Lex Web, 2013 y especialmente el ilustrativo trabajo de Duce, M. \& C. Riego, "La Prisión Preventiva en Chile: El Impacto de la Reforma Procesal Penal y Sus Cambios Posteriores”, Prisión Preventiva y Reforma Procesal Penal en América Latina: Evaluación y Perspectivas, Centro de Estudios de Justicia de las Américas, Santiago, 2009, 151-212.

${ }^{30}$ Cfr., Maier, J.B., Derecho Procesal Penal: Fundamentos, 1, del Puerto, Buenos Aires, 2004, p. 521, Paulesu, P. P., La presunzione di non colpevolezza dell'imputato, 30, G. Giappichelli, Torino, 2009, p. 77.

${ }^{31}$ Los dos últimos caracteres están estrechamente vinculados, en el sentido en que, mientras la legalidad (iii) limitaría la discrecionalidad judicial, la jurisdiccionalidad (iv) evitaría el encarcelamiento mediante 
implica que la aplicación de la medida a cada caso concreto ha de serlo mediante una decisión judicial en la que se justifique tanto la validez de la premisa normativa que establece las condiciones a que se supedita el encarcelamiento cuanto la presencia de la hechos condicionantes, premisa fáctica. Muy sintéticamente, según la concepción cautelar, las condiciones normativas de aplicación de la prisión preventiva (cuya prueba en cada caso se requiere) son entonces: (i) la correlativa al fumus boni iuris del derecho procesal civil, que en el campo del derecho procesal penal suele denominarse fumus commissi delicti: la existencia de un determinado caudal probatorio en favor de esa hipótesis acusatoria (i.e. la comisión de un delito y la participación del imputado en él); (ii) la correlativa al periculum in mora del derecho procesal civil, que en el campo del derecho procesal penal suele denominarse periculum libertatis: la probabilidad de frustración de los fines del proceso como contrafáctico del estado de libertad del acusado (i.e. el peligro de que el acusado ejecute una acción que frustre dichos fines en caso de ser dejado en libertad); (iii) el hecho de ser la prisión preventiva condición necesaria de la neutralización de dicho peligro procesal (i.e. el ser imprescindible la prisión para evitar la frustración de los fines procesales) ${ }^{32}$. En lo que aquí importa, se sigue entonces que la justificación

mecanismos legales automáticos (cfr. De Caro, A., "Presupposti e criteri applicativi”, en Spangher, G. \& A. Scalfati, Trattato di procedura penale: Prove e misure cautelari, II.2, UTET Giuridica, Torino, 2008, 5-96, p. 35, Ferrajoli, L., Derecho y razón: teoría del garantismo penal, Trotta, Madrid, 2005, p. 555).

32 Sin ánimo de exhaustividad, sobre la concepción cautelar pueden verse, Balcarce, F. I., Medidas limitativas de la libertad individual, Mediterránea, Córdoba, 2006, p. 286, Barona Vilar, S., Prisión provisional y medidas alternativas, Librería Bosch, Barcelona, 1988, Barona Vilar, S., Medidas cautelares penales - Nuevo proceso penal boliviano, El país, Santa Cruz de la Sierra, 2006, p. 27, Cafferata Nores, J. I., La excarcelación, I, Depalma, Buenos Aires, 1988, p. 32, Chiara Díaz, C. A., Las medidas de coerción y la inconstitucionalidad de la prisión preventiva, Nova Tesis, Santa Fe, 2007, De Caro, A., Libertà personale e sistema processuale penale, Edizioni Scientifiche Italiane, Napoli - Roma, 2000, p. 284, De Caro, A., "Presupposti e criteri applicativi", en Spangher \& Scalfati, Trattato di procedura penale: Prove e misure cautelari, II.2, UTET Giuridica, Torino, 2008, 5-96, p. 25, De Caro, A., "Presupposti e criteri applicativi”, en Spangher \& Scalfati, Trattato di procedura penale: Prove e misure cautelari, II.2, UTET Giuridica, Torino, 2008, 5-96, p. 37, De Luca, G., Lineamenti della tutela cautelare penale: la carcerazione preventiva, CEDAM, Padova, 1953, p. 6, Diddi, A., "Tipologia di Misure”, en Spangher, G. \& A. Scalfati, Trattato di procedura penale: Prove e misure cautelari, II.2, UTET Giuridica, Torino, 2008, 97-152, Fùrfaro, S., "Le limitazioni alla libertà personale consentite", en Spangher, G. \& C. Santoriello, Le misure cautelari personali, 1, G. Giappichelli, Torino, 2009, 1-94, p. 75, García Caba, W. R., Detención Preventiva y el presupuesto de "la gravedad de la pena que podría llegar a imponerse" en el peligro de fuga, Temis, La Paz, 2009, p. 51, Gozaíni, O. A., "La libertad en el proceso penal”, en Revista de Derecho Procesal Penal: excarcelación, 2005, 43-56, p. 56, Grevi, V., Misure cautelari e diritto di difesa nella L. 8 agosto 1995 n. 332, Giuffrè, Milano, 1996, p. 299, Maier, J.B. J., Cuestiones fundamentales sobre la libertad del imputado y su situación en el proceso penal, LEA, Buenos Aires, 1981, p. 24-25, Maier, J.B., Derecho Procesal Penal: Fundamentos, 1, del Puerto, Buenos Aires, 2004, p. 514, Maier, J.B., Derecho Procesal Penal: Actos Procesales, 3, del Puerto, Buenos Aires, 2011, p. 385-386, Nardiello, G., La prisión procesal, Ediciones Ciudad Argentina - Hispania Libros, Buenos Aires - Madrid - México, 2007, p. 13-14, Nogueira Alcalá, H., "Consideraciones sobre el derecho fundamental a la presunción de inocencia", en Ius et Praxis, 11, 2005, 221-241, Núñez, R., Código Procesal Penal de la Provincia de Córdoba, Lerner, Córdoba, 2007, p. 338, Ortiz Díaz, C., "Sobre prisión preventiva, y relación con el supuesto de peligrosidad: Análisis contemporáneo, soluciones y consideraciones, del supuesto de peligrosidad”, Paulesu, P. P., La presunzione di non colpevolezza dell'imputato, 30, G. Giappichelli, Torino, 2009, p. 68, Pessoa, N. R., Fundamentos constitucionales de la exención de prisión y de la excarcelación, Hammurabi, Buenos Aires, 1992, p. 33, Solimine, M.A., Tratado sobre 
de la premisa normativa de toda decisión judicial que aplique la prisión preventiva así concebida quedará entonces insoslayablemente ligada a la justificación de la concepción cautelar en sí misma, esto es, deberá dar cuenta de por qué está justificado encarcelar durante el proceso en esas circunstancias.

\section{LA CONCEPCIÓN CAUTELAR DE LA PRISIÓN PREVENTIVA Y LA JUSTIFICACIÓN DE LA PREMISA NORMATIVA DE LA DECISIÓN JUDICIAL}

Los argumentos dogmáticos reconstruidos en lo que precede tuvieron amplia receptación en la jurisprudencia occidental. Los tribunales son explícitos al formular las premisas normativas como instancias de la concepción cautelar, incluidos los organismos jurisdiccionales supraestatales ${ }^{33}$. Así, por ejemplo, para la Corte Suprema de Chile la normativa supralegal excluye a la prisión preventiva como regla general respecto de quienes están sometidos a juzgamiento. Sin embargo, ello no obsta a que la libertad quede subordinada al aseguramiento de la comparecencia del acusado al juicio (o incluso, a cualquier otro acto de diligenciamiento procesal) y de la eventual ejecución del fallo condenatorio $^{34}$. En Argentina, aunque la prisión preventiva se encuentra autónomamente regulada en una pluralidad de ordenamientos procesales diversos ${ }^{35}$, la cuestión de la justificación de la premisa normativa se resuelve en todas las jurisdicciones de

las causales de excarcelación y prisión preventiva en el Código Procesal Penal de la Nación, Ad-Hoc, Buenos Aires, 2003, p. 20, Villanueva, J. C. R., Medidas cautelares en el proceso penal, Omeba, Cochabamba, 2010, p. 50, Vivas Ussher, G., Manual de Derecho Procesal Penal, 2, Alveroni, Córdoba, 1999, p. 147-148.

33 Claro que ello en concordancia con textos también homogéneos: Así lo ha pretendido incluso alguna jurisprudencia argentina al decir que, "[t]odas las Constituciones de los países occidentales, junto con los tratados de derechos humanos, tienen la visión de que la coerción del imputado es la excepción y que su restricción o limitación solo es posible para asegurar cautelarmente que el proceso pueda desenvolverse para sus fines: falseamiento de las pruebas y posibilidad de cumplimiento de la pena” (CNCCorr., Sala I, Barbará, Rodrigo Ruy, 10/11/2003). En lo que sigue las referencias jurisprudenciales serán efectuadas deliberadamente en términos muy generales lo que, sin olvidar las relevantes diferencias y los matices entre los diversos ordenamientos tomados en consideración, es suficiente a los efectos de este trabajo que pretende solamente mostrar cómo los jueces interpretan los enunciados en concordancia con la concepción cautelar.

${ }^{34}$ Entre otras, CSCh, Causa No 192/2009. Resolución N ${ }^{\circ} 1202$, Sala Segunda (Penal), 13 de enero de 2009. Esto se sigue, sobre todo del texto de los artículos 122, 139, 140 y concordantes del CPP chileno. Lo mismo se desprende de muchos textos legales en vigor en otros países latinoamericanos: artículos 9, 243, 250 Código Orgánico Procesal Penal Venezuela; 253 CPP Perú; 10 y 238 CPP Costa Rica; 234, 236,237 y concs. CPP Paraguay; 2, 295, 296 CPP Colombia; 259, 261 y concs. CPP Guatemala; 166, 173 y concs. CPP Nicaragua; 178 CPP Honduras; 233 CPP Bolivia.

${ }^{35}$ Ello debido a que las provincias que componen la federación se han reservado la competencia legislativa en materia procesal, lo que conduce a que haya tantas regulaciones cuanto provincias (más la Ciudad Autónoma de Buenos Aires que no tiene tal carácter), lo que hace a un total de veinticuatro (Arts. 5, 121, 123 y 75 inc. $12 \mathrm{CN}$ ). A ellas ha de adicionarse además la relativa al código de procedimiento penal de la Nación que rige en aquellos casos sobre los que, extraordinariamente, resulta competente el Poder Judicial Nacional (Arts. 116, 117 y 75 inc. $30 \mathrm{CN}$ ). 
manera similar: se concibe a la prisión preventiva como medida cautelar con las características mencionadas en el apartado anterior ${ }^{36}$. Esto, por lo demás, en consonancia con la posición de la CSJN ${ }^{37}$. Pero ante todo, la jurisprudencia chilena y argentina, salvo contadas excepciones, se adecuan en estos aspectos a la del resto de Latinoamérica, y ello en consonancia con la jurisprudencia de la $\mathrm{CIDH}^{38}$. En sentido claramente similar, para tomar un ejemplo europeo, la custodia cautelare in carcere tal como se la denomina en la República de Italia, está regulada en el código de procedimiento correspondiente entre las "misure cautelari" que disciplina las limitaciones a la libertad de la persona ${ }^{39}$. En lo que aquí concierne, basta con remarcar que la jurisprudencia es enfática respecto de la necesidad de verificación (i) de las exigencias cautelares y (ii) de que toda otra medida de coerción se presente como inadecuada a los fines propuestos ${ }^{40}$. Esto es coincidente con la jurisprudencia de la CEDH para la que la aplicación de la prisión preventiva, en toda la comunidad europea, "deve apparire come la soluzione estrema che si giustifica solamente allorché tutte le altre opzioni disponibili si rivelino insufficienti” ${ }^{41}$. Y todo esto es incluso extensible al common law, aun cuando los sistemas de enjuiciamiento sean radicalmente diversos en otros aspectos. En efecto, el equivalente a la prisión preventiva en el sistema de enjuiciamiento de los Estados Unidos, denominado bail denial, se considera

36 Puede tomarse como un ejemplo paradigmático a nivel provincial TSJC, Aguirre Domínguez, 11/12/1997. Ya los textos legales parecen presuponer esta asunción por parte del legislador; por todos, artículos 281 CPPC, 269 CPPT, 292 CPPCat., 280 CPPN, 253 CPPTF, 253 CPPLP, 280 CPPER, 269 CPPC, 213 CPPCh y 261 CPPRN, 144 CPPBA.

${ }^{37}$ Especialmente desde CSJN, Todres, Isaac, 18/08/1971, publicado en LLO.

38 "En el caso de las medidas cautelares - a la cabeza, la prisión preventiva-, también compete a la ley, no al juzgador, prever la existencia de la medida, pero solo debiera corresponder al segundo, amparado en el acervo de datos que tiene a la mano y considerando los fines que se pretende alcanzar con la medida $-\mathrm{y}$ que, por ende, legitiman su aplicación-, aplicar esta" (CIDH, López Álvarez c. Honduras, 1/02/06, del voto del Dr. López García, considerandos 23 y 24 . El resaltado es propio. Sobre los fines buscados se remite al fallo citado). Refiere a la 'unificación latinoamericana' en la concepción de la prisión preventiva, entre otros, Zavala Baquerizo, J., Tratado de Derecho procesal penal, VI, EDINO, Quito, 2005, p. 86 y sgts.

${ }^{39}$ La técnica legislativa italiana tiene en cualquier caso la particularidad de prever presupuestos comunes a la aplicación de todas las medidas de coerción personal (no solo relativos a la prisión preventiva) pero esto no es determinante a nuestros fines. Cfr. Amodio, E., G. Amato, \& O. Dominioni, Commentario del nuovo codice di procedura penale, 3, Giuffrè, Milano, 1990, p. 6.

${ }^{40}$ Este es el marco que constituye lo que la CC denomina quadro costituzionale di riferimento: "che le condizioni e i presupposti per l'applicazione di una misura cautelare restrittiva della libertà personale siano apprezzati e motivati dal giudice sulla base della situazione concreta, alla stregua dei ricordati principi di adeguatezza, proporzionalità, e minor sacrificio, così da realizzare una piena 'individualizzazione' della coercizione cautelare" (CC, n. 265, 2010). La CCI, por su parte, se ha pronunciado concordantemente, entre otras, en sentencias n. 295 del 2005 y 164, del 2011. Ver sobre el punto, De Caro, A., Libertà personale e sistema processuale penale, Edizioni Scientifiche Italiane, Napoli - Roma, 2000, p. 170, Fùrfaro, S., 'Le limitazioni alla libertà personale consentite', en Spangher \& Santoriello, Le misure cautelari personali, 1, G. Giappichelli, Torino, 2009, 1-94, p. 73, Garofoli, V., Diritto processuale penale, Giuffrè, Milano, 2008, p. 246-247. Sobre la situación española puede verse Barona Vilar, S., Prisión provisional y medidas alternativas, Librería Bosch, Barcelona, 1988, p. 69.

${ }^{41} \mathrm{CEDH}$, en Vafiadis c. Grecia y Lelièvre c. Bélgica. 
también condicionado en su aplicación a la verificación de subsistencia de los peligros antes referidos en conjunción con la insuficiencia de la fianza para neutralizarlos ${ }^{42}$.

Es claro entonces que los jueces asumen en general que la premisa normativa que dispone la aplicación de la prisión preventiva está justificada si es concebida ella cautelarmente (i.e. supeditada a la comprobación de los supuestos de fumus commissi delicti; periculum libertatis e indispensabilidad). No obstante, lo cierto es que tal asunción carece de aptitud justificativa de por sí. Cabría preguntarse todavía cuáles son las razones que hacen que encarcelar imputados esté justificado en esos supuestos. Y es precisamente la ausencia o insuficiencia de tales razones lo que enfatizan los críticos que insisten en la incompatibilidad absoluta de la prisión preventiva con la presunción de inocencia y el derecho a la libertad ambulatoria durante el proceso penal. En lo que sigue presentaré más detalladamente algunos aspectos de la concepción cautelar a los fines de situar y analizar a las críticas a ella dirigidas.

\subsection{Los fines de la prisión preventiva como componente descriptivo: una crítica mal dirigida}

Como se ha visto, la concepción cautelar de la prisión preventiva se basa en una distinción conceptual entre ella y la prisión como pena, distinción que constituye un presupuesto insoslayable del argumento que pretende mantener fuera del campo prohibitivo de la presunción de inocencia a la prisión preventiva ${ }^{43}$. Esta distinción pretende fundarse, al menos en principio, en ciertas propiedades externas del instituto, ciertas características distintivas que el fenómeno presentaría desde el punto de vista empírico

42 "In our society, liberty is the norm, and detention prior to trial or without trial is the carefully limited exception" (USC, United States v. Salerno, 481, U.S. 739 a 755, 1987). La USC sostuvo sobre el punto que: "For our system of justice has always and quite properly functioned on the assumption that probable cause to believe (1) that a person has committed a crime, and (2) that, absent the posting of bail, he poses at least some risk of flight, justifies pretrial detention to ensure his presence at trial" (USC, Bell v. Wolfish, 441 U.S. 520, 1979). Por lo demás, la historia del instituto no es absolutamente paralela al de su versión continental. En efecto, la "Judiciary Act" de 1789 estipulaba que todos los imputados por delitos que no previesen pena capital habrían de quedar en libertad bajo fianza. Lo que nosotros conocemos como prisión preventiva se introdujo mediante la "Bail reform act of 1966", que admitió la detención ante el temor de no concurrencia al juicio. Por su parte, el distrito de Columbia fue el primero en legislar acerca de la posibilidad de encarcelar preventivamente en vistas a la protección de la comunidad. Ello habría conducido al caso States v. Edwards que allanó el camino para la vigente Bail Reform Act de 1984 (Cfr. Vannostrand, M. \& G. Keebler, "Our Journey Toward Pretrial Justice", en Federal Probation, 71, 2007, 20-25, p. 20): "Specifically, the Bail Reform Act of 1984 permits the federal courts to base pretrial release decisions on (1) the risk of pretrial flight the defendant poses, and (2) the potential threat the defendant poses to the community or to specific individuals including the likelihood that the defendant would commit new crimes while on release" (Vannostrand, M. \& G. Keebler, "Pretrial Risk Assessment in the Federal Court", en Federal Probation, 73 , 2009, 3-29, p. 4). Sobre el punto también Allen, R. J. \& L. Laudan, 'Deadly Dilemmas III: Some Kind Words for Preventive Detention', en Journal of Criminal Law and Criminology, /101, February 4, 2011, 781-802.

${ }^{43}$ Una vía alternativa sería, claro está, renunciar a esa distinción y argumentar que hay al menos un caso en que, por la razón que fuere, la presunción de inocencia se repliega, admite alguna clase de excepción y que en función de ello es el caso que alguien puede ser penado sin proceso previo concluido por condena firme. No obstante no es esta una estrategia argumental que se encuentre presente entre juristas y jueces en la actualidad. 
y que pueden ser asumidas como conceptualmente relevantes sin comprometerse desde el punto de vista justificativo ${ }^{44}$. Específicamente, según la concepción cautelar, la propiedad relevante que hace que la prisión preventiva no sea pena sino algo distinto, es el específico fin adjudicado a ella en conjunción con la ausencia de fines punitivos. Se trataría así de un discurso que explica, o pretende explicar qué es la prisión preventiva.

En este orden de ideas, los autores críticos parecen muchas veces basar su pretensión de no justificación o ilegitimidad de la prisión preventiva en la negación de esta distinción sobre la base de que el encarcelamiento "tiene siempre naturaleza de pena" ${ }^{45}$. Los fundamentos en que estas afirmaciones se basan se reducen en general a las idénticas consecuencias que el encarcelamiento tiene para la persona encerrada, sea cual fuere el fin institucional en cada caso ${ }^{46}$. Sin embargo, estas críticas no solo no logran dar en el blanco sino que además oscurecen notablemente el punto de discusión. En primer lugar, la crítica no da en el blanco porque arguye la falta de justificación de la prisión preventiva negando una distinción conceptual que, al menos en principio, puede asumirse como meramente descriptivas ${ }^{47}$. La crítica sería adecuada si demostrase que de becho la prisión preventiva no es distinta a la prisión como pena, mostrando que es empíricamente falso que su finalidad sea la de tutelar los fines del proceso y/o que se aplique ante la

${ }^{44}$ Sobre la distinción descripción/justificación, cfr., entre otros, Bayón Mohino, J. C., La normatividad del derecho: deber jurídico y razones para la acción, Centro de Estudios Constitucionales, Madrid, 1991, Redondo, M.C., La noción de razón para la acción en el análisis jurídico, Centro de Estudios Constitucionales, Madrid, 1996, p. 80, Von Wright, G. H., Spiegazione e comprensione, Il mulino, Bologna, 1977, Von Wright, G. H., "Spiegazione e comprensione dell' azione", en Egidi, R., Mente, azionen, libertà: Saggi 1983-2003, Quodlibet, Macerata, 1983, 43-58.

${ }^{45}$ Vitale, G., Encarcelamiento de presuntos inocentes: Hacia la abolición de una barbarie, Hammurabi, Buenos Aires, 2007, p. 59. Así también Ferrajoli: “[e]s un mísero paralogismo decir que la cárcel preventiva no contradice el principio nulla poena sine iudicio - es decir, la jurisdiccionalidad en el sentido más lato- porque no es una pena sino otra cosa: medida cautelar, procesal o en todo caso no penal. Con parecidos fraudes de etiquetas (...) se ha disuelto -en el nuestro como en otros ordenamientos- la función de tutela del derecho penal y el papel mismo de la pena como medida punitiva exclusiva, alternativa a otras seguramente más eficaces pero no tan garantistas" (Ferrajoli, L., Derecho y razón: teoría del garantismo penal, Trotta, Madrid, 2005, p. 556). En idéntico sentido Kees, J. M., "La peligrosidad en las medidas personales de coerción”, en Pensamiento Penal, 2006, afirmando que "no es posible distinguir el encarcelamiento punitivo del preventivo aun si este último es dispuesto solo como un instrumento de neutralización de eventuales riesgos procesales" y Bovino al decir que "[e]l principio de inocencia no existe para prohibir al Estado imponer al inocente medidas sustancialmente represivas con fines también represivos, sino para probibir al Estado imponer al inocente toda medida sustancialmente represiva, independientemente de los fines atribuidos a tal medida" (Bovino, A., Justicia penal y derechos humanos, Editores del Puerto, Buenos Aires, 2005a, p. 98 y también Bovino, A., "Contra la inocencia”, en Revista electrónica de derecho penal, derecho procesal penal y criminología, 2005b).

46 Identidad que ya señalara reiteradamente Francesco Carrara. Por todos, Carrara, F., "Inmoralità del carcere preventivo", Programma del corso di diritto criminale: del giudizio criminale, Il Mulino, Bologna, 2004 [1872], 401-405.

${ }^{47}$ Se ha dicho que los desacuerdos que pueden presentarse en relación con los conceptos son de dos clases: (i) puramente teóricos, "acerca de cómo reconstruir el concepto correspondiente para maximizar su adecuación a la realidad", y (ii) valorativos, "acerca de cómo construirlos para que peritan una mejor aplicación del Derecho (esto es, una aplicación del mismo más ajustada a nuestras intuiciones, creencias morales, sentido del Derecho, etc.)" (González Lagier, D., "Hechos y conceptos”, en Dialnet: cuadernos electrónicos de filosofía del derecho, 15, marzo, 2007a) 
necesidad de esa tutela ${ }^{48}$. Sin embargo, no es esta la estrategia de los críticos; ellos se limitan a negar la posibilidad de distinción sin más pretendiendo que se siga de allí la falta de justificación. En este sentido, con argumentos tales no se lograría dar cuenta de distinciones usuales y ampliamente intuitivas en el derecho, como la que se suele hacer entre pena de multa y obligación de pagar impuestos, o incluso entre diversas formas de privación de la libertad ${ }^{49}$. En segundo lugar, este modo de plantear la crítica tiene el defecto de oscurecer el desacuerdo y la cuestión relevante a resolver, esto es, aquella consistente en determinar si está o no justificado (o si lo estaría) encarcelar a individuos con la finalidad (exclusiva) de tutelar los fines del proceso penal. Y oscurece el punto precisamente porque fenómenos distintos requieren justificaciones distintas ${ }^{50}$. De esto me ocuparé en lo que queda de este trabajo.

\subsection{Los fines de la prisión preventiva como componente normativo: fin como justificación del medio}

La distinción conceptual que conduce a la aseveración de que la prisión preventiva no es pena, sino medida cautelar (de modo que no afecta al principio de presunción de inocencia), no dice nada todavía acerca de por qué está justificado encarcelar cautelarmente. Lo único que de allí se sigue, a lo sumo, es que encarcelar de ese modo no está prohibido por (cierta interpretación de) la presunción de inocencia. Sin embargo, las bases mismas de la concepción cautelar de la prisión preventiva como medida excepcionalmente limitativa de derechos constitucionales exigen una justificación independiente de la premisa normativa resultante de tal concepción. Y una justificación tal depende de la presencia de determinada clase de razones, no ya explicativas de la prisión preventiva como fenómeno particular, sino más bien normativas: justificativas

${ }^{48}$ Creo que el único modo de comprobar la adecuación empírica de la distinción es relevando lo que los jueces efectivamente hacen cuando aplican la prisión preventiva. Esto podría evidenciarse en el modo en que justifican externamente sus decisiones. En este sentido, la descripción de la prisión preventiva como "medida cautelar dispuesta para neutralizar los peligros que se ciernen sobre los fines del proceso" será adecuada si los decisores aplican la prisión preventiva ante la comprobación de tales peligros y de la indispensabilidad de tal medida para neutralizarlos. Me he ocupado de esto en el trabajo más general del que algunas de las ideas que aquí se exponen forman parte, llegando a la conclusión de que la concepción cautelar es impracticable si asume seriamente sus compromisos. No puedo ocuparme de ese problema aquí pero he adelantado mi intuición en la nota 11. Por lo demás, la corrección de esta descripción no obsta a que el encarcelamiento preventivo aplicado produzca, a veces o siempre, otras consecuencias ulteriores, como la de neutralizar al individuo si, por caso, fuese peligroso; amedrentar a todos los potenciales delincuentes en libertad; etc. Cfr. Asencio Mellado, J. M., La prisión provisional, Civitas, Madrid, 1987, p. 37.

49 "El Estado tiene autoridad para privar a la gente de su libertad en una forma similar a la pena, pero que en realidad no es una pena. Así, para proteger a las personas el Estado puede imponer internaciones temporales de personas que representan un serio peligro para otras. También existe la cuarentena para personas aquejadas de determinadas enfermedades infecciosas, o la internación en un centro de enfermos mentales. Las razones y justificaciones de estas otras formas de privación de libertad individual requieren también de una elaboración" (Fletcher, G. P., Gramática del derecho penal, Hammurabi, Buenos Aires, 2007, p. 306). El resaltado es propio.

${ }^{50}$ Cfr. Raz, J., Razón práctica y normas, Centro de Estudios Constitucionales, Madrid, 1991, p. 18. 
de la afirmación de que la necesidad de tutela de los fines del proceso penal puestos en peligro (o cualquier otra cosa que quisiese alegarse) obliga a privar de la libertad a una persona no condenada. El problema reside en que, como se vio, la cuestión de la prisión preventiva pareciera estar gobernada por una regla general que es la del mantenimiento de la libertad de las personas no condenadas. Esta regla se derivaría de una serie de ya aludidos principios, a los que se reconoce de modo prácticamente unánime en occidente una jerarquía privilegiada dentro del ordenamiento jurídico ${ }^{51}$. Esto significa (de acuerdo con la teoría de las fuentes más expandida en la cultura jurídica occidental) que se trata de postulados que no pueden ser dejados de lado, contradichos o desconocidos por leyes jerárquicamente inferiores y que sus desplazamientos solo podrían estar justificados sobre la base de postulados de un orden jerárquico idéntico o superior ponderados como prevalecientes en ese caso o clase de $\operatorname{casos}^{52}$. En efecto, a diferencia de lo que sucede con los conflictos o antinomias entre reglas ${ }^{53}$; los principios serían algo así como mandatos de optimización, normas que mandarían a realizar un valor en la mayor medida de lo posible ${ }^{54}$. La colisión entre principios se resolvería mediante un balance de la dimensión de peso que estos, a diferencia de las reglas, poseerían. No se trataría ni de introducir excepciones ni de invalidar uno de los estándares, sino más bien de un desplazamiento por otro principio que, al menos para ese caso en particular (o clase de casos), resultaría prevaleciente en peso ${ }^{55}$.

Esto parece poner de manifiesto ciertas suposiciones subyacentes a la concepción cautelar de la prisión preventiva y que están presentes (a veces expresamente) en las decisiones que en ella se basan. En este orden de ideas, la postura de los decisores que afirman que la regla según la cual los imputados deben estar en libertad (fundada en los principios constitucionales pertinentes), debe ser dejada de lado en ciertas circunstancias

${ }^{51}$ Cfr. Nino, C. S., Fundamentos de derecho constitucional: Análisis filosófico, jurídico y politológico de la práctica constitucional, Astrea, Buenos Aires, 2005, p. 254-255.

52 Por todos, Dworkin, R., Law's empire, Belknap Press of Harvard University Press, Cambridge [etc.], 1986, Dworkin, R. M., Los Derechos en serio, Ariel, Barcelona, 2002, Moreso, J. J., "Conflitti tra princìpi costituzionali", en Diritto E questioni pubbliche, 2, 2002, 19-34, Moreso, J. J., La Constitución: modelo para armar, Marcial Pons, Madrid-Barcelona-Buenos Aires, 2009.

53 Esto es, los casos en que dos reglas del sistema correlacionan el mismo caso con dos soluciones contradictorias, y que se resolverían bien reduciendo el ámbito de aplicación de una de las reglas, bien declarando inválida a una de ellas, entre otros, por aplicación del criterio de jerarquía de fuentes. Cfr. Alexy, R., Teoría de los derechos fundamentales, Centro de Estudios Políticos y Constitucionales, Madrid, 2008 [1986], p. 69, Moreso, J. J., La Constitución: modelo para armar, Marcial Pons, Madrid-Barcelona-Buenos Aires, 2009, p. 310. Las reglas, se dice, son más resistentes al balance porque siempre pueden ser resultado de una interpretación adecuadora (ver, Pino, G., Diritti e interpretazione: il ragionamento giuridico nello Stato costituzionale, Il mulino, Bologna, 2010, cap. VII, 2.2.).

54 Alexy, R., Teoría de los derechos fundamentales, Centro de Estudios Políticos y Constitucionales, Madrid, 2008 [1986], p. 67. Sobre el punto ver también, Atienza, M., Las razones del derecho: teorías de la argumentación jurídica, Universidad Nacional Autónoma de México, México, 2003, p. 174-175. La cuestión no es en absoluto pacífica, pero no es posible ocuparse de esto aquí.

${ }^{55}$ Una buena explicación de la técnica argumentativa de la ponderación (distinguida de la "lógica ponderativa" subyacente a ciertos argumentos diversos), en Pino, G., Diritti e interpretazione: il ragionamento giuridico nello Stato costituzionale, Il mulino, Bologna, 2010, cap. VII, especialmente punto 1.2. 
de necesidad cautelar solo es plausible sobre la base de dos suposiciones que, sin embargo, parecen sumamente discutibles. La primera de ellas consiste, trivialmente, en asumir que los estándares del balance se encuentran en el mismo estrato jerárquico (o, en su defecto, que aquellos que conducen a la búsqueda de los fines del proceso estarían en un estrato superior), de modo que se da un caso de colisión entre principios "constitucionales": entre aquel que garantiza la libertad durante el proceso (fuente de la regla objeto de excepción) por un lado, y algún otro principio del que se derive el deber de proteger los fines del proceso penal, por el otro. Si así no fuere, el derecho a la libertad durante el proceso no podría ser desplazado, ya que su jerarquía lo impediría. La segunda suposición consiste en que el principio presupuesto en primer término pesa más, al menos en algún caso o clase de casos, que aquel que informa el derecho a la libertad, que en consecuencia debe ser desplazado en ese caso o clase de $\operatorname{casos}^{56}$. Sin embargo, las razones que informan el balance que justifica la premisa normativa basada en la concepción cautelar no son del todo transparentes. Consideraremos estas dos asunciones a continuación.

\subsubsection{La cautela procesal como cuestión de principios: una crítica posible}

Es un lugar común entre quienes se identifican con la concepción cautelar de la prisión preventiva el situar jerárquicamente el principio de tutela de los fines procesales en ciertas expresiones presentes en algunas disposiciones constitucionales. La CN argentina, por ejemplo, prevé en su artículo 18, que nadie puede "ser arrestado sino en virtud de orden escrita de autoridad competente". Los juristas sostienen, a contrario sensu, que la propia CN estaría previendo alguna clase de privación de la libertad antes de la condena legítima si ordenada por escrito y por autoridad competente ${ }^{57}$. Aunque no es determinante, no puede dejar de llamarse la atención sobre esta interpretación acrítica de arresto en el texto constitucional como referente a cualquier medida de privación de

${ }^{56}$ En el sentido de que "[1] as condiciones en las cuales un principio tiene precedencia sobre otro constituyen el supuesto de hecho de una regla que expresa la consecuencia jurídica del principio precedente" (Alexy, R., Teoría de los derechos fundamentales, Centro de Estudios Políticos y Constitucionales, Madrid, 2008 [1986], p. 75). Para la "concepción cautelar": si fumus bonis iuris, periculum libertatis e indispensabilidad, entonces, prisión preventiva. En el common law, en el mismo sentido, "[ $\mathrm{t}]$ he bail decision is a reflection of pretrial justice; it is the primary attempt to balance the rights afforded to accused persons awaiting trial with the need to protect community maintain the integrity of the judicial process, and assure court appearance" (Vannostrand, M. \& G. Keebler, "Our Journey Toward Pretrial Justice”, en Federal Probation, 71, 2007, 20-25, p. 20). Cfr. también, aunque no referido exclusivamente al mismo problema, Alschuler, A. W., "Preventive pretrial detention and the failure of interest balancing approaches to due process", en Michigan Law Review, 85, 1986-1987, 510-569.

57 "No parece existir el menor signo de duda de que la voz arrestado utilizada por nuestra Constitución vale lo mismo que detenido preventivamente o, más genéricamente, privado de la libertad locomotiva" (Maier, J.B. J., Cuestiones fundamentales sobre la libertad del imputado y su situación en el proceso penal, LEA, Buenos Aires, 1981, p. 27, también en Maier, J.B., Derecho Procesal Penal: Fundamentos, 1, del Puerto, Buenos Aires, 2004, p. 511). En el mismo sentido, entre muchos otros, Cafferata Nores, J. I., La excarcelación, I, Depalma, Buenos Aires, 1988, p. 7. Ver también, CSJN, Todres, Isaac, 18/08/1971, publicado en LLO. Sobre el argumento interpretativo a contrario y su carácter de falacia véase Guastini, R., Estudios sobre la interpretación jurídica, Universidad Autónoma de México, México, 1999, p. 28. 
la libertad de locomoción (sea más o menos gravosa) y no como "arresto" en sentido técnico. En efecto, prácticamente la totalidad de los códigos procesales así como los procesalistas distinguen y han distinguido históricamente diversas medidas de coerción personal, siendo el arresto tan solo una de ellas: medida de coerción sumamente breve y condicionada por circunstancias específicas ${ }^{58}$. Entender que la $\mathrm{CN}$ utiliza el término impropiamente y en un sentido más amplio al que le es propio implica una interpretación extensiva, perjudicial para el imputado y, por ello, indudablemente conflictiva con otras disposiciones ${ }^{59}$. En cualquier caso, lo cierto es que fuera de estos supuestos donde la terminología es dudosa, es frecuente en la actualidad encontrar en los ordenamientos, disposiciones constitucionales, u otras equiparadas a ellas, que aluden expresamente a la “prisión preventiva”. El primero es, entre otros, el caso de la Constitución Política de la República de Chile que establece en su artículo 19 inc. 7) que "[1]a libertad provisional procederá a menos que la detención o la prisión preventiva sea considerada por el juez como necesaria para las investigaciones del sumario o para la seguridad del ofendido o de la sociedad. La ley establecerá los requisitos y modalidades para obtenerla...”. Asimismo, en Italia el artículo 13 de la Constitución contiene una disposición que en su última parte dispone: "La legge stabilisce i limiti massimi della carcerazione preventiva" 60 . Y disposiciones similares pueden encontrarse en ciertos tratados internacionales que suelen ser usados para ubicar a la prisión preventiva en la cúspide de la jerarquía de fuentes ${ }^{61}$. Así, la mención se entiende como tolerancia, y la tolerancia se ubica a nivel supralegal ${ }^{62}$. Pues bien, frente a esta asunción la crítica "radical” adquiere cierta plausibilidad: lo que ella podría pretender es que la distinción conceptual entre prisión punitiva y preventiva (aunque posible) no puede (deóntico) tener relevancia práctica, porque en cualquier caso, aunque se trate de fenómenos teleológicamente diversificados (y por tanto, con-

58 En este sentido Vitale, G., Encarcelamiento de presuntos inocentes: Hacia la abolición de una barbarie, Hammurabi, Buenos Aires, 2007, p. 94-95.

${ }^{59}$ Esto es así por varias razones. La primera de ellas es que, asumiendo que el in dubio pro reo rige también en materia interpretativa sería un caso de violación a la regla que de él derivaría: interpretar restrictivamente todo cuanto tenga que ver con la privación de la libertad de las personas. En segundo lugar, dejando al margen la aplicabilidad de tal principio, es un tanto paradojal fundar en una interpretación extensiva toda una concepción (la de la coerción personal en el proceso penal) pretendidamente regida por el principio de interpretación restrictiva (por derivación del carácter de "excepcionalidad” cautelar). Y en ambos casos, aunque esto no es determinante, cabe decir que se trataría de una interpretación antiliberal de la CN por cuanto implica la ampliación del ámbito de facultades del Estado en perjuicio de las libertades que aquella vendría a garantizar. Sobre este tipo de interpretación, Guastini, R., Estudios sobre la interpretación jurídica, Universidad Autónoma de México, México, 1999, p. 84-85. Véanse también Calsamiglia, A., "Ensayo sobre Dworkin", en Dworkin, R. M., Los Derechos en serio, Ariel, Barcelona, 2002, 7-29, p. 17, Dworkin, R. M., Los Derechos en serio, Ariel, Barcelona, 2002, p. 152.

${ }^{60}$ La misma constitución alude además al arresto y a la detención en el artículo $682^{\circ}$.

${ }^{61}$ Ver especialmente para Latinoamérica artículos 7.5. de la CADH y 9.3. del PIDCP.

${ }^{62}$ Entre otros, Ottaviano, S., “'‘Libertad provisional' o 'derecho a la libertad'?: La libertad del imputado durante el proceso a la luz de los instrumentos internacionales de derechos humanos”, en Revista de Derecho Procesal Penal: excarcelación, 2005, 393-426, p. 413-414, Pessoa, N. R., "En torno a la libertad durante el proceso penal”, en Revista de Derecho Procesal Penal: excarcelación, 2005, 57-68, p. 61. Estas interpretaciones serían pasibles de algunas de las críticas precedentemente expuestas en contra de la interpretación a contrario. 
ceptualmente distinguibles), la libertad estaría garantizada por principios a los que la cautela procesal no puede afectar por su inferioridad jerárquica. Así, la crítica se torna tan plausible cuanto discutibles son los argumentos que ubican a la prisión preventiva (o a los principios que la informan) a nivel supralegal. En cualquier caso, dejaré esto de lado en lo que sigue, ya que aun concediendo esos razonamientos que ubican a la justificación de la prisión preventiva como "cuestión de principios", en rigor, todavía nada se sigue de allí en relación con los casos en que esa privación de la libertad estaría justificada constitucionalmente ${ }^{63}$. Me centraré en esto a continuación.

\subsubsection{El peso de los fines del proceso penal: un caso de duda}

La insuficiencia de la mera "mención" no es del todo pasada por alto por los defensores de la concepción cautelar de la prisión preventiva. Por ello, la argumentación tradicional de dicha concepción suele complementarse con la idea, de raigambre iluminista, de que esa justificación ha de buscarse en la tutela de los fines del proceso como valor particularmente relevante, superior (al menos en ciertas circunstancias) al valor individual de libertad personal desde que "así lo exige el deber de realizar justicia" Argumentos de este tipo pueden encontrarse incluso en los textos de algunos organismos internacionales encargados de la interpretación y/o aplicación de los tratados antes aludidos $^{65}$. Se seguiría de allí que en las circunstancias de la colisión, i.e. aquellas en que la libertad del imputado hace peligrar la realización del debido proceso y sus fines de descubrimiento de la verdad y ejecución de la ley penal (y por tanto, "la búsqueda misma de la justicia”), habría de introducirse la excepción de prisión preventiva a la regla de mantenimiento de libertad ${ }^{66}$. El argumento consiste en mostrar a la prisión preventiva como medio necesario para la realización del fin justicia en ciertas circunstancias. Esto tiene

63 En efecto, "admitir no equivale a imponer o exigir" (Gialdino, R. E., "La prisión preventiva en el derecho internacional de los derechos humanos", en Revista Investigaciones: Secretaría de Investigación de Derecho Comparado de la Corte Suprema de Justicia de la Nación Argentina, 2000, 2000).

${ }^{64}$ En Argentina esta particular relevancia justificativa de la función de la prisión preventiva (i.e. de la tutela de los fines del proceso), se ha sostenido llamativamente, surgiría del preámbulo de la $\mathrm{CN}$, “... la finalidad de 'afianzar la justicia' hacia la cual se orienta el 'juicio previo', requiere: a) que no se impida ni obstaculice su realización; b) que sus conclusiones se asienten sobre la verdad; c) que se cumpla efectivamente lo que en él se resuelva" (Cafferata Nores, J. I., La excarcelación, I, Depalma, Buenos Aires, 1988, p. 4-5). "Si el imputado, aprovechando su libertad, pudiera impedir la condena (falseando las pruebas o no compareciendo al proceso) o eludir el cumplimiento de la pena (fugando), la 'justicia', lejos de ser afianzada, sería burlada" (Cafferata Nores, J. I., La excarcelación, I, Depalma, Buenos Aires, 1988, p. 5). En idéntico sentido, entre otros, Chiara Díaz, C., "El proceso penal y la coerción personal”, en Revista de Derecho Procesal Penal: excarcelación, 2005, 13-33, p. 15. Cfr. sobre el punto también Pérez Barberá, G., "Prisión preventiva y excarcelación”, en La Ley Córdoba, 1992, 1072.

65 Por todos, CoIDH, informe 2/97; CEDH, entre otros, Stögmüller v. Austria, del 10 de noviembre de 1969; Letellier c. Francia, del 26 de junio de 1991; Tomasi c. Francia, del 27 de agosto de 1992; Toth c. Austria, del 12 de diciembre de 1991, etcétera.

${ }^{66}$ Cfr. Gozaíni, O. A., "La libertad en el proceso penal", en Revista de Derecho Procesal Penal: excarcelación, 2005, 43-56, p. 45-46. 
por lo menos dos implicancias que aquí interesa resaltar, una fáctica y una normativa. (i) En primer lugar, implica formular una proposición fáctica de aquellas que describen los medios que son condición necesaria, indispensable, para la consecución de determinados estados de $\operatorname{cosas}^{67}$. Se trata de proposiciones descriptivas (por tanto, con valor de verdad) que, ante un genuino deber de lograr ese estado de cosas (e.g. tutelar los fines del proceso) determinan lo que tiene que hacerse necesariamente a los fines de satisfacerlo, en el sentido de regla técnica ${ }^{68}$. Pues bien, muchas veces las críticas a la justificación de la prisión preventiva parecen atacar esta implicancia, basándose en la pretendida falta de necesidad del medio para el fin ${ }^{69}$. Sin embargo, en estos casos las críticas se tornan en buena medida inocuas al confundir la cuestión fáctico-probatoria, consistente en la efectiva necesidad del medio para el fin, con la cuestión relativa la justificación del medio pretendidamente necesario ${ }^{70}$. Negar la necesidad de la prisión preventiva -e incluso probar la ausencia de tal necesidad-nada dice acerca de su justificación llegado el caso en que ella fuere efectivamente necesaria ${ }^{71}$. (ii) Pero en cualquier caso, y en segundo lugar, lo

67 Y que Von Wright denominó anankásticas (Von Wright, G. H., Norma y acción: una investigación lógica, Tecnos, Madrid, 1979, p. 29). Sobre el punto, Manrique, M. L., P. E. Navarro, \& J. M. Peralta, La relevancia de la dogmática penal, Universidad Externado de Colombia, Bogotá, 2011. González Lagier, D., “Algunas precisiones sobre la noción de contenido normativo en Normative Systems", en Moreso, J. J. \& M.C. Redondo, Filosofía y derecho (Marcial Pons), Marcial Pons, Madrid, 2007b, 109-116, p. 114.

${ }^{68}$ Von Wright, G. H., Norma y acción: una investigación lógica, Tecnos, Madrid, 1979, p. 29-30. Sobre la explicitación de reglas técnicas como función de la dogmática, Manrique, M. L., P. E. Navarro, \& J. M. Peralta, La relevancia de la dogmática penal, Universidad Externado de Colombia, Bogotá, 2011, p. 36-40.

${ }^{69}$ Por ejemplo, Ferrajoli fundamenta (parte de) su afirmación acerca de la "ilegitimidad" de la prisión preventiva en la pretensión de que ella no es (empíricamente) necesaria para los fines que se propone. Sería (a) innecesaria probatoriamente debido a que, “... una exigencia de esta clase puede verse satisfecha, mejor que por la prisión cautelar, por el simple traslado coactivo del imputado ante el juez y su detención por el tiempo estrictamente necesario -horas o al máximo días, pero no años- para interrogarlo en una audiencia preliminar o en un incidente probatorio y quizá para realizar las primeras comprobaciones acerca de sus disculpas" (Ferrajoli, L., Derecho y razón: teoría del garantismo penal, Trotta, Madrid, 2005, p. 557) ; o más aún, “... dentro de una concepción cognoscitivista y acusatoria del proceso, la prisión provisional no solo no es necesaria sino que resulta perjudicial para la averiguación de la verdad por el cauce del juicio contradictorio" (Ferrajoli, L., Derecho y razón: teoría del garantismo penal, Trotta, Madrid, 2005, p. 558). Y sería además (b) innecesaria para evitar la fuga del imputado, ya que sería muy difícil, "en una sociedad informatizada e internacionalmente integrada como la actual, una fuga definitiva; y tal vez bastaría como medio disuasorio una mayor vigilancia del imputado, sobre todo en los días inmediatamente anteriores a la sentencia (...) cuando la fuga hiciera perder la pista del imputado, se habría conseguido en la mayor parte de los casos el efecto de neutralizarlo, dando así satisfacción a los fines preventivos del derecho penal" (Ferrajoli, L., Derecho y razón: teoría del garantismo penal, Trotta, Madrid, 2005, p. 559). Se esfuerza también en mostrar la inadecuación empírica de la prisión preventiva como medio necesario para los fines propuestos Vitale, G., Encarcelamiento de presuntos inocentes: Hacia la abolición de una barbarie, Hammurabi, Buenos Aires, 2007, p. 124. En contraste, alude a la presencia de necesidad empírica Maier, J.B., Derecho Procesal Penal: Actos Procesales, 3, del Puerto, Buenos Aires, 2011, p. 382.

${ }^{70}$ De hecho, podría comprobarse, por ejemplo, que torturar a la gente es medio necesario para lograr un determinado fin valioso y todavía negarse que torturar esté justificado. $\mathrm{O}$ a la inversa, negar que sea necesario, pero argumentar que estaría justificado si lo fuere.

${ }^{71}$ Ver también, Juliano, M.A., "La Naturaleza Encubierta del Fenómeno de la Prisión Preventiva”, en Revista Latinoamericana de Derecho Penal y Criminología, IJ-VL-456, 2006. 
cierto es que los defensores de la concepción cautelar no se limitan a afirmar la relación de necesidad, sino que presentan a la prisión preventiva precisamente como institución que forma parte de un ideal normativo: argumentan que ella, siendo además necesaria, está justificada porque los fines para los que es necesaria son indispensables para la realización de "la justicia" 72 . Es aquí donde la crítica radical parece cobrar más fuerza si es planteada en los términos correctos. En efecto, varios autores han sostenido que resulta arbitrario afirmar que ese sea el contenido del afianzamiento de la justicia. Uno podría entender que afianzar la justicia implica más bien no encarcelar a quienes son presumidos inocentes hasta la condena ${ }^{73}$. Pero a este punto, el nivel de discusión parece trascender al plano "meramente" jurídico y dependerá de las razones en favor de considerar a la "justicia" de tal o cual modo ${ }^{74}$. Podría señalarse quizás, de modo inconcluyente, que el considerar a la prisión preventiva una expresión del afianzamiento de la justicia no resulta del todo coherente desde el punto de vista "axiológico-constitucional”, al menos no frente a otras asunciones frecuentes. Así, aunque se abogue por el "descubrimiento de la verdad" y la aplicación y ejecución de la ley penal como fines del proceso penal, lo cierto es que, “... desde que se reformó el procedimiento inquisitivo y se aceptó políticamente, que a pesar de que el procedimiento penal sirve, principalmente, a la meta de averiguar la verdad objetiva sobre un suceso histórico, él constituye un método regulado -no libre- para arribar a ese fin, con lo que fueron excluidas, absoluta o relativamente, algunas formas de investigar la verdad, debido a principios superiores que protegen la dignidad esencial del hombre, el fin de arribar a la verdad histórica para lograr la correcta actuación de la ley penal, aun en perjuicio del imputado, no justifica la utilización de medios probibidos de investigación"75. En este sentido, la idea de exclusión de medios de prueba en vistas a la tutela de ciertos derechos individuales parece resultado de una ponderación cuya conclusión va en perjuicio del "descubrimiento de la verdad"

\footnotetext{
${ }^{72}$ Véase el argumento de Nino, C. S., Fundamentos de derecho constitucional: Análisis filosófico, jurídico y politológico de la práctica constitucional, Astrea, Buenos Aires, 2005, p. 255.

73 Así piensa por ejemplo Vitale al decir que "[e]l uso efectivo de la cárcel para quienes no han sido condenados, lejos de afianzar la justicia, la quebranta mortalmente, pues pretende asegurar finalidades procesales a través de la violación de normas jurídicas de mayor jerarquía” (Vitale, G., Encarcelamiento de presuntos inocentes: Hacia la abolición de una barbarie, Hammurabi, Buenos Aires, 2007, p. 100); "todo arresto sin juicio ofende el sentimiento común de justicia" (Ferrajoli, L., Derecho y razón: teoría del garantismo penal, Trotta, Madrid, 2005, p. 555). En el mismo sentido, Bovino, A., Justicia penal y derechos bumanos, Editores del Puerto, Buenos Aires, 2005a, p. 99 y algunas lecturas de Maier: "El riesgo de su fuga (...) que supone tolerar la privación de libertad durante el procedimiento pese a afirmar la posibilidad cierta de que incluso la condena no determine el ingreso a una cárcel, sumados a la subversión de principios básicos del procedimiento penal, los de inocencia y juicio previo, resulta menor en importancia que la injerencia en la libertad locomotiva, así injusta por desproporcionada en esos casos" (Maier, J.B., Derecho Procesal Penal: Actos Procesales, 3, del Puerto, Buenos Aires, 2011, p. 418).

${ }^{74}$ Lo que es indispensable si se pretende concebir a la ponderación como una actividad racional y no meramente como un juicio subjetivo de valor (sobre el punto Pino, G., Diritti e interpretazione: il ragionamento giuridico nello Stato costituzionale, Il mulino, Bologna, 2010, cap. VII, punto 3).

${ }^{75}$ Maier, J.B., Derecho Procesal Penal: Fundamentos, 1, del Puerto, Buenos Aires, 2004, p. 703.
} 
y de la ejecución de la ley penal sustantiva ${ }^{76}$. A esto se agrega que al mismo tiempo se asume la garantía de no aplicación de consecuencias penales en todos los casos en que no pueda justificadamente afirmarse que los enunciados fácticos condicionantes están probados $^{77}$. De este modo se garantiza (i) el abandono de la pretensión punitiva si no se puede afirmar (según el estándar de prueba) que es verdad la proposición que afirma la culpabilidad del imputado y (ii) el abandono de la pretensión probatoria si ello implica avasallar ciertos derechos individuales. Ambos postulados se garantizan por un medio: el proceso penal. Siendo esto así, pues entonces no parece del todo coherente pretender que está justificada la prisión preventiva como aseguramiento de los fines del proceso, concibiendo de tal modo como medio (i.e. la privación de libertad) para asegurar el fin del proceso, aquello que el proceso como medio se propone evitar. Lo axiológicamente incoherente sería renunciar a los fines del proceso en tutela de derechos como la intimidad hogareña, la intimidad personal, las relaciones familiares, etc., mas no hacerlo frente a la libertad ambulatoria de las personas.

En cualquier caso, al margen de esto, una alternativa justificativa al mero recurso al "afianzamiento de la justicia", ha sido buscada en la prohibición de desarrollar el proceso penal o, más concretamente, su etapa plenaria, el juicio, en rebeldía ${ }^{78}$. La prohibición de juicio penal en ausencia del imputado obedecería a la necesidad de garantizar su defensa en un sentido más estricto que en otros tipos de procedimiento, asumiéndose que su presencia deviene indispensable ${ }^{79}$. De tal modo, la garantía de defensa en juicio

${ }^{76}$ Entre otros, Ferrer Beltrán, J., La valoración racional de la prueba, Marcial Pons, Madrid, 2007, p. 80, Maier, J.B., Derecho Procesal Penal: Actos Procesales, 3, del Puerto, Buenos Aires, 2011, p. 95. Aunque esto no es pacífico lo cierto es que esta "ponderación" no es estable: "tampoco es posible olvidar que en el procedimiento penal tiene excepcional relevancia y debe ser siempre tutelado 'el interés público que reclama la determinación de la verdad en el juicio', ya que aquel no es sino el medio para alcanzar los valores más altos: la verdad y la justicia (C. S. de EE.UU., Stone vs. Powell, 428 U. S. 465, 1976, en p. 488, y la cita de D. H. Oaks en nota 30, p. 491). De manera, pues, que el deber de dejar establecida la verdad jurídica objetiva, en materia de enjuiciamiento penal, solo autoriza a prescindir, por ilícita, de una prueba cuando ella, en sí misma, haya sido obtenida por medios inconstitucionales o ilegales" (CSJN, Fernández, Víctor H., 12/11/1990). Ver Maier, J.B., Derecho Procesal Penal: Fundamentos, 1, del Puerto, Buenos Aires, 2004 , p. 704, comentando el fallo citado.

77 "Y ello no por razones epistemológicas, sino por el coste del riesgo de error sobre los bienes en juego" (Ferrer Beltrán, J., La valoración racional de la prueba, Marcial Pons, Madrid, 2007, p. 83), es decir, por razones morales. Ver lo dicho supra sobre los aspectos probatorios de la presunción de inocencia.

${ }^{78}$ El fundamento "es racional porque, no concibiéndose el proceso penal contumacial (en ausencia del imputado o en rebeldía), por razones que derivan del principio de inviolabilidad de su defensa, su presencia es necesaria para poder conducir el procedimiento hasta la decisión final e, incluso, para ejecutar la condena eventual que se le imponga, especialmente la pena privativa de la libertad, y su ausencia (fuga) impide el procedimiento de persecución penal, al menos en su momento decisivo (juicio plenario), y el cumplimiento de la eventual condena" (Maier, J.B., Derecho Procesal Penal: Fundamentos, 1, del Puerto, Buenos Aires, 2004, p. 517).

${ }^{79}$ No alcanzaría, "con solo conceder una posibilidad cierta de defenderse, sin controlar de hecho que quien se defiende pueda, realmente, ejercer esa defensa; al contrario, necesita verificar, de cuerpo presente, que el imputado sea idóneo para intervenir en el procedimiento (capacidad) y esté en condiciones para ejercer las facultades que, al efecto, le concede la ley procesal penal" (Maier, J.B., Derecho Procesal Penal: Fundamentos, 1, del Puerto, Buenos Aires, 2004, p. 595). 
se vuelve perjudicial para todos aquellos de quienes pueda predicarse la peligrosidad de fuga. Los críticos afirman frente a esto que, “... el poder estatal de privar de la libertad individual a la persona procesada no puede apoyarse en una garantía que protege dicha libertad, en la medida en que se funda en la inviolabilidad de la defensa en juicio" 80 . Esto se funda en una asunción más general según la cual las garantías no pueden en ningún caso representar un perjuicio para sus titulares. En este sentido, podría incluso asumirse que el proceso mismo representa una garantía y que, como tal, trasciende a los fines (así subordinados) de descubrimiento de la verdad y actuación de la ley penal sustantiva. Probablemente esto esté por detrás de la crítica radical que aquí se analiza ${ }^{81}$. De lo que se trataría (asumiendo que la razón por la que la prisión preventiva se torna normativamente necesaria es la garantía de defensa en juicio) es de ponderar entre esa garantía y aquella de libertad durante el proceso. Y efectivamente, no resulta en absoluto concluyente que la segunda ceda sin más: que sea más justo encerrar preventivamente que desarrollar un proceso en rebeldía ${ }^{82}$. Claro que, sin embargo, aun admitiendo el juicio en rebeldía, todavía se mantendría el problema de la ejecución de la pena privativa de la libertad. Y es precisamente este problema el que ha llevado a algunos autores a sostener que la prisión preventiva está justificada como conditio sine qua non del proceso penal mismo, como componente suyo inescindible en cuya ausencia el proceso deviene imposible ${ }^{83}$. Tal como la entiendo, la idea de fondo reside en que, previéndose la ejecución de una pena contra la voluntad del condenado decidida en un proceso, necesariamente ha de preverse la posibilidad de garantizar esa potencial ejecución desde el comienzo mismo del proceso. Y no habría otro modo de hacerlo que privando de la libertad al posible condenado, al menos en ciertas circunstancias. No obstante, el argumento parece incurrir en una petitio principii. En efecto, presentar a la prisión preventiva como instituto justificado por resultar consustancial al proceso penal presupone (además de la relación de necesidad -fáctica- del medio para el fin) la supremacía de ese fin frente a

\footnotetext{
${ }^{80}$ Vitale, G., Encarcelamiento de presuntos inocentes: Hacia la abolición de una barbarie, Hammurabi, Buenos Aires, 2007, p. 106.

${ }^{81}$ En esta orientación parecen ir ciertos argumentos presentes en Rusconi, M.A., "Prisión preventiva y límites del poder penal del Estado en el sistema de enjuiciamiento”, en La Ley, 1997-E, 1997, 1363, Zaffaroni, E. R., A. Alagia, \& A. Slokar, Derecho penal: Parte general, EDIAR, Buenos Aires, 2002, p. 169. Por lo demás, es conocida la posición de Ferrajoli (acaso meramente conjetural) en cuanto a que "[e]l peligro de fuga, de hecho, está provocado predominantemente, más que por el temor a la pena, por el miedo a la prisión preventiva. Si el imputado no estuviera ante esta perspectiva, tendría, por el contrario, al menos hasta la víspera de la condena, el máximo interés en no escapar y defenderse" (Ferrajoli, L., Derecho y razón: teoría del garantismo penal, Trotta, Madrid, 2005, p. 558).

${ }^{82}$ Julio Maier, flexibilizando la posición que históricamente había mantenido al respecto, dijo recientemente, “... creo que la única manera de ser medianamente consecuente con la afirmación de inocencia y la nulla coactio hasta la condena firme, es, para mal o para bien, tolerar el procedimiento penal en rebeldía o en ausencia del imputado..." (Maier, J.B., Derecho Procesal Penal: Actos Procesales, 3, del Puerto, Buenos Aires, 2011, p. 383).

${ }^{83}$ En este sentido Pastor, D. R., "Las funciones de la prisión preventiva", en Revista de Derecho Procesal Penal: La injerencia en los derechos fundamentales del imputado, 2006-1, 2006, Paulesu, P. P., La presunzione di non colpevolezza dell'imputato, 30, G. Giappichelli, Torino, 2009, p. 71.
} 
los valores en conflicto. Por el contrario, el que los fines del proceso no puedan lograrse (en algunos casos) a causa del respeto del derecho a estar libre el imputado durante el proceso (y por el abuso de este) podría ser justamente el costo a pagar por la afirmación y respeto de ese derecho. Pretender que la imposibilidad de lograr esos fines a causa de ese ejercicio justifica la imposición de la prisión preventiva presupone lo que hay que probar: que esos fines pesan más (al menos en esos casos de posible frustración) que el derecho a permanecer en libertad. Como fuere, el resultado de la ponderación no parece en ninguno de los casos concluyente.

\section{Consideraciones finales}

Lo hasta aquí dicho pone de manifiesto la pretensión de legitimidad de la prisión preventiva si cautelarmente concebida no se ve afectada por la crítica que niega la distinción conceptual entre prisión preventiva y pena de prisión. Se ha mostrado además que esa pretensión tampoco se ve afectada por la negación de ser el encarcelamiento empíricamente necesario para el logro de un determinado fin ${ }^{84}$. La pretensión de legitimidad se ve desafiada tan solo afirmando que el encarcelamiento dispuesto con finalidad cautelar (siendo o no necesario para el fin) constituye una violación no tolerada constitucionalmente a los derechos a la libertad ambulatoria y a ser tratado como inocente hasta la condena. El hecho de que desde los orígenes mismos de la presunción de inocencia y hasta la fecha se haya aceptado a la prisión preventiva como medida cautelar poco dice frente a esta afirmación. Un crítico diría que ese es precisamente el error. Así vista la cuestión, el desacuerdo queda bien delimitado, pero se muestra como uno de esos desacuerdos que trascienden al marco "meramente jurídico" y donde las herramientas para su resolución son escasas ${ }^{85}$. Esto no implica deslegitimar los esfuerzos de los aquí llamados críticos radicales, sino más bien todo lo contrario. Los argumentos críticos en conjunción con lo inconcluyente (y acaso incoherente) de los argumentos de quienes defienden la concepción cautelar de la prisión preventiva ponen en tela de juicio a la justificación de las premisas normativas fundadas en esa concepción, cargando sobre las espaldas de los jueces el peso de ofrecer argumentos adicionales en favor de esas premisas, argumentos que excedan la mera repetición de cuanto implica la concepción cautelar.

\footnotetext{
nota 48$)$

85 “... la controversia ha de ser acuñada en términos filosóficos: el uso de confesiones obtenidas sin asesoramiento jurídico o la detención preventiva, ¿contradicen los principios morales que están en la base de las doctrinas establecidas? Yo creo que sí, pero todavía falta que la jurisprudencia tienda los puentes entre la teoría jurídica y la teoría moral que fundamenta esa afirmación” (Dworkin, R. M., Los Derechos en serio, Ariel, Barcelona, 2002, p. 59). En la misma orientación, Ferrajoli ha señalado que "[e]ste interrogante debe ser afrontado sobre todo desde el punto de vista externo, prescindiendo de lo que dice la Constitución, para de este modo no sucumbir a la falacia hoy habitual en nuestra cultura jurídica, según la cual lo que por hipótesis la Constitución consiente es también justo e incontestable" (Ferrajoli, L., Derecho y razón: teoría del garantismo penal, Trotta, Madrid, 2005, p. 556).
}

${ }^{84}$ En rigor, se ha dicho, podría haber un desacuerdo sobre estos puntos pero sería de otra índole (ver 
Estos argumentos brillan por su ausencia en la práctica jurisprudencial. Sin embargo, ya que son aparentemente los jueces mismos quienes tienen el poder de determinar cuál es el contenido de la "dimensión axiológica" del ordenamiento jurídico, cuál es el contenido constitucionalmente admisible de los enunciados expresivos de reglas, pareciera que no queda más que resignarse a reconocer que la prisión preventiva está “jurídicamente justificada" casi "universalmente" 86 . Ello es así aun cuando lo esté por argumentos, como mínimo, dudosos. Y si esto es así, habrá que reconocer además que no es este un ámbito en que los jueces consideren aplicable el in dubio pro reo en materia interpretativa ${ }^{87}$.

\section{BIBLIOGRAFÍA}

Alexy, R., Teoría de los derechos fundamentales, Centro de Estudios Políticos y Constitucionales, Madrid, 2008 [1986].

Alschuler, A. W., "Preventive pretrial detention and the failure of interest balancing approaches to due process", en Michigan Law Review, 85, 1986-1987, 510-569.

Alvarado Velloso, A., Introducción al estudio del derecho procesal, 1, Rubinzal-Culzoni, Santa Fe, 2008.

Allen, R. J. \& L. Laudan, "Deadly Dilemmas III: Some Kind Words for Preventive Detention”, en Journal of Criminal Law and Criminology, /101, February 4, 2011, 781-802.

Amodio, E., G. Amato, \& O. Dominioni, Commentario del nuovo codice di procedura penale, 3, Giuffrè, Milano, 1990.

Asencio Mellado, J. M., La prisión provisional, Civitas, Madrid, 1987.

Atienza, M., Las razones del derecho: teorías de la argumentación jurídica, Universidad Nacional Autónoma de México, México, 2003.

Balcarce, F. I., Medidas limitativas de la libertad individual, Mediterránea, Córdoba, 2006.

BArgis, M., "Procedimento de libertate e giudicato cautelare", en Associazione tra gli studiosi del processo penale, Presunzione di non colpevolezza e disciplina delle impugnazioni, Giuffrè, Milano, 2000, 165-191.

Barona Vilar, S., Prisión provisional y medidas alternativas, Librería Bosch, Barcelona, 1988.

Barona Vilar, S., Medidas cautelares penales - Nuevo proceso penal boliviano, El país, Santa Cruz de la Sierra, 2006.

Batia, G. \& A. Pizzo, "La tutela dell' imputato - Saggio storico - concettuale”. <http://www. diritto.it/archivio/1/20757.pdf>.

Bayón Mohino, J. C., La normatividad del derecho: deber jurídico y razones para la acción, Centro de Estudios Constitucionales, Madrid, 1991.

Beccaria, C., Dei delitti e delle pene, Verona, 1996 [1764].

Bidart Campos, G. J., Tratado elemental de Derecho constitucional argentino, I-A, EDIAR, Buenos Aires, 2000.

Binder, A. M., Introducción al derecho procesal penal, Ad-Hoc, Buenos Aires, 2009.

86 A ello se suma, claro está, el respaldo "democrático" de la literalidad de los textos de los códigos de procedimiento que regulan la prisión preventiva y que los jueces interpretan.

${ }^{87}$ Quedará por analizar cuánto lo sea en materia probatoria centrándose en las razones por las que los jueces afirman que hay periculum libertatis en tal o cual caso y que lo hay en una magnitud tal que hace indispensable el encarcelamiento. 
Bovino, A., Justicia penal y derechos humanos, Editores del Puerto, Buenos Aires, 2005 a.

Bovino, A., "Contra la inocencia", en Revista electrónica de derecho penal, derecho procesal penal y criminología, 2005b.

Bovino, A., "Un Voto Cínico. A propósito del Voto de Riggi en el caso Chabán", en Nueva Doctrina Penal, 1, 2006, 127-157.

Bulygin, E., "Sobre el estatus ontológico de los derechos humanos", en Doxa: Cuadernos de Filosofía del Derecho, 4, 1987, 79-85.

Cafferata Nores, J. I., La excarcelación, I, Depalma, Buenos Aires, 1988.

Calamandrei, P., Introduzione allo studio sistematico del provvedimenti cautelari, CEDAM, Padova, 1936.

Calsamiglia, A., "Ensayo sobre Dworkin”, en Ronald M. Dworkin, Los Derechos en serio, Ariel, Barcelona, 2002, 7-29.

Carcano, D. \& A. Fojadelli, "Custodia cautelare" e libertà personale, CEDAM, Padova, 1985.

Carrara, F., Programma del corso di diritto criminale: del giudizio criminale, Il Mulino, Bologna, 2004 [1859].

Carrara, F., "Inmoralità del carcere preventivo", Programma del corso di diritto criminale: del giudizio criminale, Il Mulino, Bologna, 2004 [1872], 401-405.

Carrara, F., "Il diritto penale e la procedura penale", Programma del corso di diritto criminale: del giudizio criminale, Il Mulino, Bologna, 2004 [1873-74], 415-441.

Clariá Olmedo, J. A., Derecho Procesal Penal, 1, Marcos Lerner, Córdoba, 1984.

Cordero, F., Riti e sapienza del diritto, Laterza, Roma-Bari, 1981.

Cordero, F., La fabbrica della peste, Laterza, Roma, 1984.

Cordero, F., Procedura penale, Giuffrè, Milano, 2003.

Chiara Díaz, C., "El proceso penal y la coerción personal”, en Revista de Derecho Procesal Penal: excarcelación, 2005, 13-33.

Chiara Díaz, C. A., Las medidas de coerción y la inconstitucionalidad de la prisión preventiva, Nova Tesis, Santa Fe, 2007.

Chiovenda, G., Istituzioni di diritto processuale civile, I, Eugenio Jovene, Napoli, 1953.

Chiovenda, G., Principii di diritto processuale civile, Eugenio Jovene, Napoli, 1965.

De Caro, A., Libertà personale e sistema processuale penale, Edizioni Scientifiche Italiane, Napoli - Roma, 2000.

De Caro, A., "Presupposti e criteri applicativi", en Giorgio Spangher \& Adolfo Scalfati, Trattato di procedura penale: Prove e misure cautelari, II.2, UTET Giuridica, Torino, 2008, 5-96.

De Lora, P., Memoria y frontera el desafío de los derechos humanos, Alianza, Madrid, 2008.

DE LuCA, G., Lineamenti della tutela cautelare penale: la carcerazione preventiva, CEDAM, Padova, 1953.

Diddi, A., 'Tipologia di Misure', en Giorgio Spangher \& Adolfo Scalfati, Trattato di procedura penale: Prove e misure cautelari, II.2, UTET Giuridica, Torino, 2008, 97-152.

Duce, M. \& C. Riego, "La Prisión Preventiva en Chile: El Impacto de la Reforma Procesal Penal y Sus Cambios Posteriores”, Prisión Preventiva y Reforma Procesal Penal en América Latina: Evaluación y Perspectivas, Centro de Estudios de Justicia de las Américas, Santiago, 2009, 151-212.

Dworkin, R., Law's empire, Belknap Press of Harvard University Press, Cambridge [etc.], 1986.

Dworkin, R. M., Los Derechos en serio, Ariel, Barcelona, 2002.

Falzone, V., F. Palermo, \& F. Cosentino, La Costituzione della Repubblica italiana: illustrata con $i$ lavori preparatori e corredata da note e riferimenti, Arnoldo Mondadori, Milano, 1976.

Fernández López, M., Prueba y presunción de inocencia, Iustel, Madrid, 2005.

Ferrajoli, L., Derecho y razón: teoría del garantismo penal, Trotta, Madrid, 2005. 
Ferrer Beltrán, J., La valoración racional de la prueba, Marcial Pons, Madrid, 2007.

Ferri, E., Sociologia criminale, Fratelli Bocca, Torino, 1892.

Ferrua, P., Studi sul processo penale: declino del contraddittorio e garantismo reattivo, III, Giappichelli, Torino, 1997.

Ferrua, P., "Il giudizio penale: fatto e valore giuridico", en A.A.V.V., La prova nel dibattimento penale, G. Giappichelli, Torino, 2007, 317-410.

Fletcher, G. P., Gramática del derecho penal, Hammurabi, Buenos Aires, 2007.

Fùrfaro, S., "Le limitazioni alla libertà personale consentite", en Giorgio Spangher \& Ciro Santoriello, Le misure cautelari personali, 1, G. Giappichelli, Torino, 2009, 1-94.

García Caba, W. R., Detención Preventiva y el presupuesto de "la gravedad de la pena que podría llegar a imponerse" en el peligro de fuga, Temis, La Paz, 2009.

Garofalo, R., Criminologia: studio sul delitto, sulle sue cause e sui mezzi di repressione, Fratelli Bocca, Roma [etc.], 1885.

Garofalo, R., "La detenzione preventiva", en La Scuola Positiva, 2, 1892, 199.

Garofoli, V., "Presunzione d'innocenza e considerazione di non colpevolezza. La fungibilitá delle due formulazioni”, en Associazione tra gli studiosi del processo penale, Presunzione di non colpevolezza e disciplina delle impugnazioni, Giuffrè, Milano, 2000, 63-104.

Garofoli, V., Diritto processuale penale, Giuffrè, Milano, 2008.

Gialdino, R. E., "La prisión preventiva en el derecho internacional de los derechos humanos", en Revista Investigaciones: Secretaría de Investigación de Derecho Comparado de la Corte Suprema de Justicia de la Nación Argentina, 2000, 2000.

Giocoli Nacci, P., "Procedimento de libertate e giudicato cautelare”, en Associazione tra gli studiosi del processo penale, Il significato del principio costituzionale di non colpevolezza dell'imputato, Giuffrè, Milano, 2000, 231-238.

Giunchedi, F., La tutela dei diritti umani nel processo penale, CEDAM, Padova, 2007.

GonZÁlez Lagier, D., "Hechos y conceptos", en Dialnet: cuadernos electrónicos de filosofía del derecho, 15, marzo, 2007a.

GonZÁlEz Lagier, D., "Algunas precisiones sobre la noción de contenido normativo en Normative Systems”, en José Juan Moreso \& María Cristina Redondo, Filosofía y derecho (Marcial Pons), Marcial Pons, Madrid, 2007b, 109-116.

Gozaíni, O. A., "La libertad en el proceso penal", en Revista de Derecho Procesal Penal: excarcelación, 2005, 43-56.

Grevi, V., Misure cautelari e diritto di difesa nella L. 8 agosto 1995 n. 332, Giuffrè, Milano, 1996.

Grevi, V., "Presunzione di non colpevolezza, garanzie dell'imputato ed efficienza del processo nel sistema costituzionale", en Associazione tra gli studiosi del processo penale, Presunzione di non colpevolezza e disciplina delle impugnazioni, Giuffrè, Milano, 2000, 15-62.

Guastini, R., Estudios sobre la interpretación jurídica, Universidad Autónoma de México, México, 1999.

Illuminati, G., La presunzione d'innocenza dell'imputato, Zanichelli, Bologna, 1979.

Juliano, M.A., "La Naturaleza Encubierta del Fenómeno de la Prisión Preventiva", en Revista Latinoamericana de Derecho Penal y Criminología, IJ-VL-456, 2006.

Kees, J. M., "La peligrosidad en las medidas personales de coerción”, en Pensamiento Penal, 2006.

Maier, J.B., Derecho Procesal Penal: Fundamentos, 1, del Puerto, Buenos Aires, 2004.

Maier, J.B., Derecho Procesal Penal: Actos Procesales, 3, del Puerto, Buenos Aires, 2011.

MAIER, J.B. J., Cuestiones fundamentales sobre la libertad del imputado y su situación en el proceso penal, LEA, Buenos Aires, 1981. 
Manrique, M. L., P. E. Navarro, \& J. M. Peralta, La relevancia de la dogmática penal, Universidad Externado de Colombia, Bogotá, 2011.

Manzini, V., Manuale di procedura penale italiana, Fratelli Bocca, Roma [etc.], 1912.

Martini, F. M. (2010), "Ilegitimidad del encarcelamiento preventivo" (Universidad Nacional de Córdoba).

Moreso, J. J., "Conflitti tra princìpi costituzionali”, en Diritto E questioni pubbliche, 2, 2002, 19-34.

Moreso, J. J., La Constitución: modelo para armar, Marcial Pons, Madrid-Barcelona-Buenos Aires, 2009.

Nardiello, G., La prisión procesal, Ediciones Ciudad Argentina - Hispania Libros, Buenos Aires - Madrid - México, 2007.

Nino, C. S., Fundamentos de derecho constitucional: Análisis filosófico, jurídico y politológico de la práctica constitucional, Astrea, Buenos Aires, 2005.

Nogueira Alcalá, H., "Consideraciones sobre el derecho fundamental a la presunción de inocencia”, en Ius et Praxis, 11, 2005, 221-241.

Núñez, R., Código Procesal Penal de la Provincia de Córdoba, Lerner, Córdoba, 2007.

Ortiz Diaz, C., "Sobre prisión preventiva, y relación con el supuesto de peligrosidad: Análisis contemporáneo, soluciones y consideraciones, del supuesto de peligrosidad”. <¡Error! Referencia de hipervínculo no válida, accessed 2 de agosto de 2013.

OtтAviano, S., “ ¿Libertad provisional’ o 'derecho a la libertad'?: la libertad del imputado durante el proceso a la luz de los instrumentos internacionales de derechos humanos”, en Revista de Derecho Procesal Penal: excarcelación, 2005, 393-426.

Pastor, D. R., “El encarcelamiento preventivo”, Tensiones: ¿Derechos fundamentales o persecución penal sin limites?, Editores del Puerto, Buenos Aires, 2004, 147-164.

Pastor, D. R., "Las funciones de la prisión preventiva", en Revista de Derecho Procesal Penal: La injerencia en los derechos fundamentales del imputado, 2006-1, 2006.

Paulesu, P. P., La presunzione di non colpevolezza dell'imputato, 30, G. Giappichelli, Torino, 2009.

PÉrez Barberá, G., “Prisión preventiva y excarcelación”, en La Ley Córdoba, 1992, 1072.

Pessoa, N. R., Fundamentos constitucionales de la exención de prisión y de la excarcelación, Hammurabi, Buenos Aires, 1992.

Pessoa, N. R., "En torno a la libertad durante el proceso penal”, en Revista de Derecho Procesal Penal: excarcelación, 2005, 57-68.

PINo, G., Diritti e interpretazione: il ragionamento giuridico nello Stato costituzionale, Il mulino, Bologna, 2010.

Pisapia, G. D., Compendio di procedura penale, CEDAM, Padova, 1985.

RaZ, J., Razón práctica y normas, Centro de Estudios Constitucionales, Madrid, 1991.

Redondo, M.C., La noción de razón para la acción en el análisis jurídico, Centro de Estudios Constitucionales, Madrid, 1996.

Rocco, A., "Relazione al progetto preliminare del codice di Procedura Penale", en Ministero della Giustizia e degli Affari di Culto. Italia, Lavori preparatori del Codice penale e del Codice di procedura penale, VIII, Tipografia delle Mantellate, Roma, 1929, 295 p.

Rusconi, M.A., "Prisión preventiva y límites del poder penal del Estado en el sistema de enjuiciamiento”, en La Ley, 1997-E, 1997, 1363.

Solimine, M.A., Tratado sobre las causales de excarcelación y prisión preventiva en el Código Procesal Penal de la Nación, Ad-Hoc, Buenos Aires, 2003.

Vannostrand, M. \& G. Keebler, “Our Journey Toward Pretrial Justice”, en Federal Probation, $71,2007,20-25$.

Vannostrand, M. \& G. Keebler, "Pretrial Risk Assessment in the Federal Court", en Federal Probation, 73, 2009, 3-29. 
Vélez Mariconde, A., Derecho procesal penal, 1, Marcos Lerner, Córdoba, Argentina, 1986.

Villanueva, J. C. R., Medidas cautelares en el proceso penal, Omeba, Cochabamba, 2010.

Vitale, G., Encarcelamiento de presuntos inocentes: Hacia la abolición de una barbarie, Hammurabi, Buenos Aires, 2007.

Vivas Ussher, G., Manual de Derecho Procesal Penal, 2, Alveroni, Córdoba, 1999.

VoN Wright, G. H., Spiegazione e comprensione, Il mulino, Bologna, 1977.

VoN Wright, G. H., Norma y acción: una investigación lógica, Tecnos, Madrid, 1979.

VoN Wright, G. H., "Spiegazione e comprensione dell' azione”, en Rosaria Egidi, Mente, azionen, libertà: Saggi 1983-2003, Quodlibet, Macerata, 1983, 43-58.

Wróblewski, J., "Legal Syllogism and Rationality of Judicial Decision", en Rechtstheorie, 5, 1974, 33-46.

Wróblewski, J., Sentido y hecho en el derecho, Distribuciones Fontamara, México, 2008.

Zaffaroni, E. R., A. Alagia, \& A. Slokar, Derecho penal: Parte general, EDIAR, Buenos Aires, 2002.

Zaffaroni, E. R., A. Alagia, \& A. Slokar, Manual de derecho penal: parte general, Ediar, Buenos Aires, 2006.

Zavala Baquerizo, J., Tratado de Derecho procesal penal, VI, EDINO, Quito, 2005. 
